\title{
Transformações de interfaces térreas, uso e percepção de segurança em cidade litorânea
}

\author{
Transformations of ground floor interfaces, use and perception of security in a \\ coastal city
}

Fabiana Bugs Antocheviz ${ }^{[a]}[(1)$, Caroline Ársego de Figueiredo[a], Antônio Tarcísio Reis[a,b] (1)

\author{
[a] Universidade Federal do Rio Grande do Sul (UFRGS), Programa de Pós-graduação em Planejamento Urbano e \\ Regional (PROPUR), Porto Alegre, RS, Brasil \\ [b] Universidade Federal do Rio Grande do Sul (UFRGS), Faculdade de Arquitetura, Porto Alegre, RS, Brasil
}

Como citar: Antocheviz, F. B., Figueiredo, C. A., \& Reis, A. T. (2019). Transformações de interfaces térreas, uso e percepção de segurança em cidade litorânea. urbe. Revista Brasileira de Gestão Urbana, 11, e20170225.

https://doi.org/10.1590/2175-3369.011.001.A014

\section{Resumo}

Este artigo tem o objetivo de examinar os impactos das transformações nas interfaces térreas das edificações, resultantes da expansão urbana de cidade litorânea, no uso dos espaços abertos públicos e na percepção de segurança dos usuários quanto à ocorrência de crimes em tais espaços públicos e em unidades residenciais adjacentes. Nove quadras, divididas em três grupos conforme o predomínio das seguintes características, foram selecionadas na cidade de Capão da Canoa: edificações com térreos residenciais com portas e janelas voltadas para a rua; edificações com comércios e serviços nos pavimentos térreos; edificações com predominância de paredes cegas e portas de garagem nos pavimentos térreos. Os dados foram coletados por meio de contagens do movimento de pedestres e de veículos e da aplicação de questionários e entrevistas com pessoas que moram, trabalham ou veraneiam nas nove quadras selecionadas. Ainda, valores de integração de tais quadras foram obtidos por análise sintática do mapa de segmentos de Capão da Canoa. Os resultados indicam, por exemplo, mais movimento de pedestres e mais percepção de segurança nas quadras com mais conexões funcional e visual entre as interfaces térreas das edificações e os espaços abertos públicos, com predomínio de comércios e serviços nos pavimentos térreos.

Palavras-chave: Interfaces térreas. Uso do espaço aberto público. Percepção de segurança. Ocorrência de crimes. Cidade litorânea.

\section{Abstract}

This paper aims to examine the impacts of transformations of buildings' ground floor interfaces, resulting from the urban expansion of a coastal city, on the use of public open spaces, and on the user's perception of security against crimes in such public spaces and in neighbouring residential units. We selected nine blocks divided into three groups in the city of Capão da Canoa, according to the predominance of the following characteristics: residential buildings with doors and windows facing the street; buildings with

FBA é mestre em Planejamento Urbano e Regional, e-mail: fabianabugs@hotmail.com

CAF é mestre em Planejamento Urbano e Regional, e-mail: carolinearsego@gmail.com

ATR é Ph.D.em Arquitetura, professor titular, e-mail: tarcisio.reis@ufrgs.br 
shops and services on the ground floor; buildings with blind walls and garages on the ground floor. Data were collected through counting of pedestrian and vehicle traffic; and the application of questionnaires and interviews with people who live, work or spend their holidays in the selected blocks. The integration values of such blocks were obtained through the syntactic analysis of the Capão da Canoa segment map. The results indicate a greater traffic of pedestrians and greater perception of security in the blocks, with greater functional and visual connection between the ground floor interfaces of the buildings and the open public space, and with predominance of shops and services on ground floors.

Keywords: Ground floor interfaces. Use of public open space. Perception of security. Occurrence of crimes. Coastal city.

\section{Introdução}

A proximidade com o mar qualifica as áreas costeiras, atrai um grande número de usuários, principalmente em épocas de veraneio, e tem promovido a expansão urbana de cidades litorâneas de pequeno porte no Brasil (Moraes, 1999). Essa expansão tem se caracterizado pela alteração dos usos nos pavimentos térreos e pela redução das permeabilidades física e visual entre as interfaces térreas das edificações e os espaços abertos públicos (Antocheviz et al., 2017). A proximidade entre as edificações e a calçada e a existência de portas e janelas voltadas para a rua, características de áreas urbanas tradicionais, criam interfaces que tendem a atrair o pedestre, gerando pontos de encontro que favorecem a socialização (Gehl, 2010). A existência de portas e janelas também possibilita mais supervisão do espaço público a partir do interior das edificações, contribuindo para mais sensação de segurança nas vias públicas (Jacobs, 2009). Pavimentos térreos com atividades comerciais também tendem a estimular a permanência das pessoas por mais tempo em determinado local, contribuindo para a percepção de mais segurança no espaço urbano (Reis \& Lay, 2006). Somado a isso, é próprio do ser humano a tendência de frequentar lugares com mais atividade e potencial de encontro com outras pessoas, como locais com bares e restaurantes voltados para a rua (Figura 1). Esse tipo de uso, normalmente, se expande para a esfera pública e cria uma nova dinâmica de interação social (Gehl, 2009). Nesse contexto, a diversidade de atividades também contribui para que pessoas com interesses distintos frequentem o espaço aberto público em horários alternados, mantendo esses locais ocupados por maiores períodos de tempo (Bentley et al., 1985).

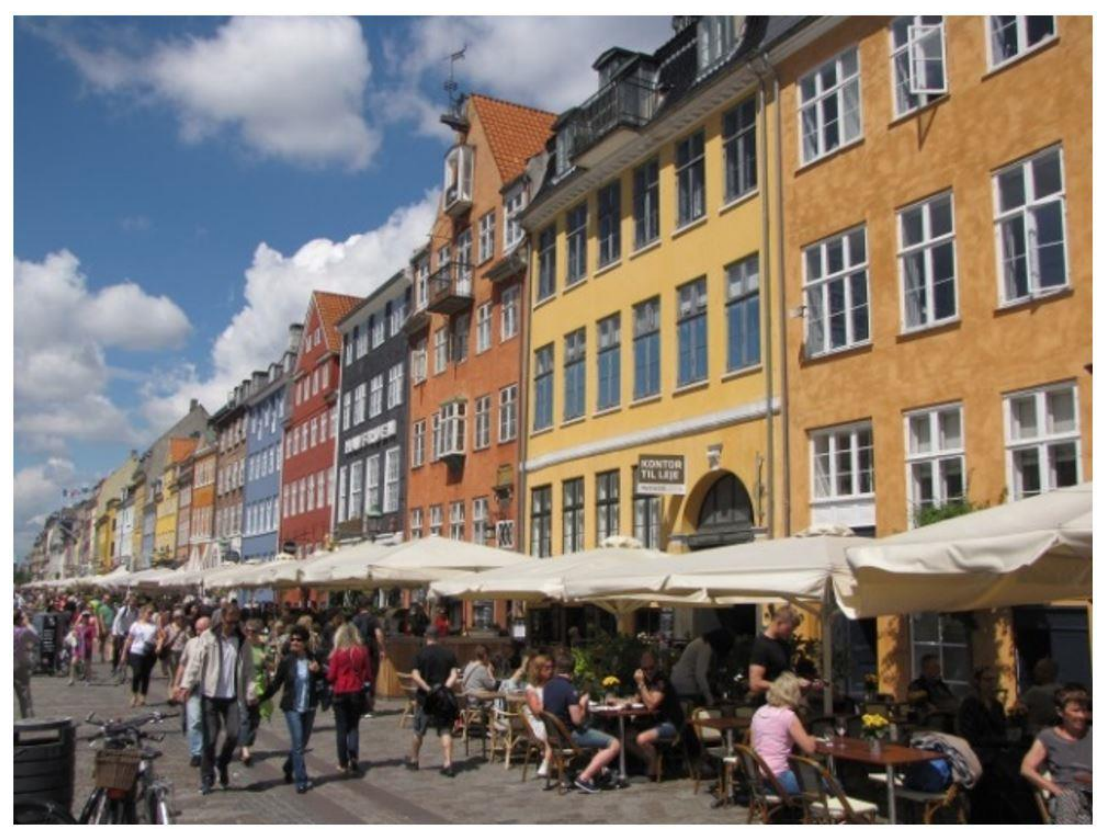

Figura 1 - Uso do pavimento térreo com atividade comercial em Copenhague, Dinamarca. Fonte: Autores (2017). 
Entretanto, nas cidades contemporâneas são recorrentes espaços urbanos flanqueados por paredes cegas ou por muros que delimitam os espaços privados e/ou semiprivados (Figura 2). Os condomínios fechados murados ou enclaves fortificados, conforme definido por Caldeira (2003), exemplificam a ruptura da relação entre as edificações e o espaço aberto público em razão da formação de barreiras físicas e visuais. Conforme Becker \& Reis (2004), espaços abertos públicos conformados por tais barreiras físicas e visuais tendem a ser percebidos como inseguros. Isso também pode ser observado em edifícios que destinam o pavimento térreo ao uso de garagens, fazendo os usuários passarem diretamente do âmbito privado para o público, sem qualquer tipo de contato físico ou visual ou que proporcione algum tipo de interação com outras pessoas (Rohmer, 2015). Assim, a baixa ocorrência de atividades e a falta de conexões físicas e visuais nos pavimentos térreos tendem a tornar o espaço urbano pouco atraente e inseguro para o pedestre, que passa a priorizar o uso de veículos (Holston, 1993).

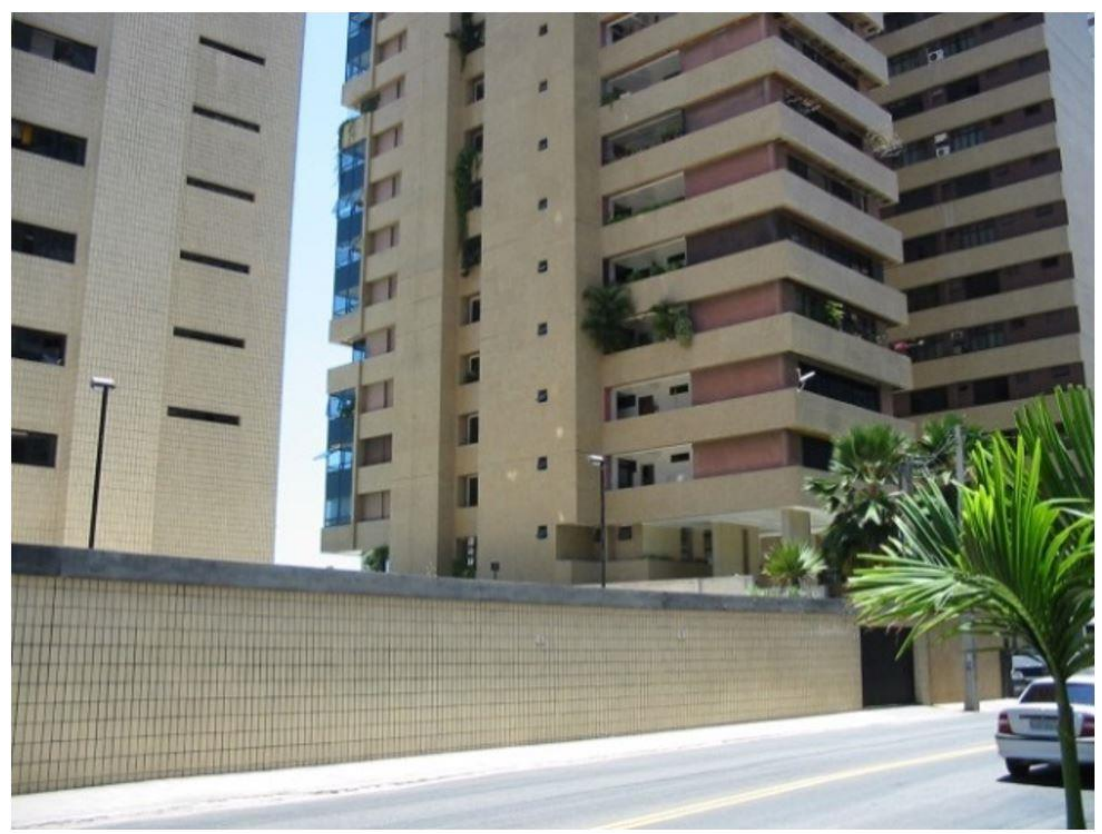

Figura 2 - Condomínio fechado murado sem conexões física e visual com o espaço urbano em Fortaleza. Fonte: Autores (2017).

Todavia, não existem evidências conclusivas a respeito dos efeitos promovidos pelas transformações nas interfaces térreas das edificações no uso dos espaços abertos públicos e na percepção de segurança quanto a crimes, especificamente, em cidades litorâneas de pequeno porte em crescente expansão urbana. Portanto, o objetivo deste artigo é avaliar os impactos das transformações nas interfaces térreas das edificações (com foco nos diferentes níveis de permeabilidades visual e funcional e usos nos térreos), no uso dos espaços abertos públicos, na percepção de segurança e nas indicações de ocorrências de crimes pelos usuários em tais espaços públicos e em unidades residenciais adjacentes.

Para que tal objetivo seja atingido de forma mais clara, também são analisados os recuos das interfaces térreas e os níveis de integrações global e local de seus segmentos (equivalente a uma quadra), já que tais aspectos também podem afetar o uso dos espaços abertos. Por exemplo, a existência de pequenos recuos frontais (de 3 a 4 metros) utilizados como área de estar tende a contribuir positivamente para a vitalidade do espaço aberto, seja este público, semiprivado ou privado (Gehl, 2010). Por sua vez, os níveis de integrações global e local dos segmentos também podem contribuir para um maior ou menor uso dos espaços abertos públicos e indicam o potencial de acessibilidade e, logo, de movimento nos segmentos, considerando a relação com todos os demais segmentos do sistema em questão - integração global (Figura 3), assim como somente os segmentos distantes a cinco passos do segmento em questão integração local (Figura 4), com as ruas mais integradas tendendo a ser mais acessíveis e a possuir mais movimento de pedestres e de veículos (Hillier \& Hanson, 1984; Hillier \& Vaughan, 2007). 


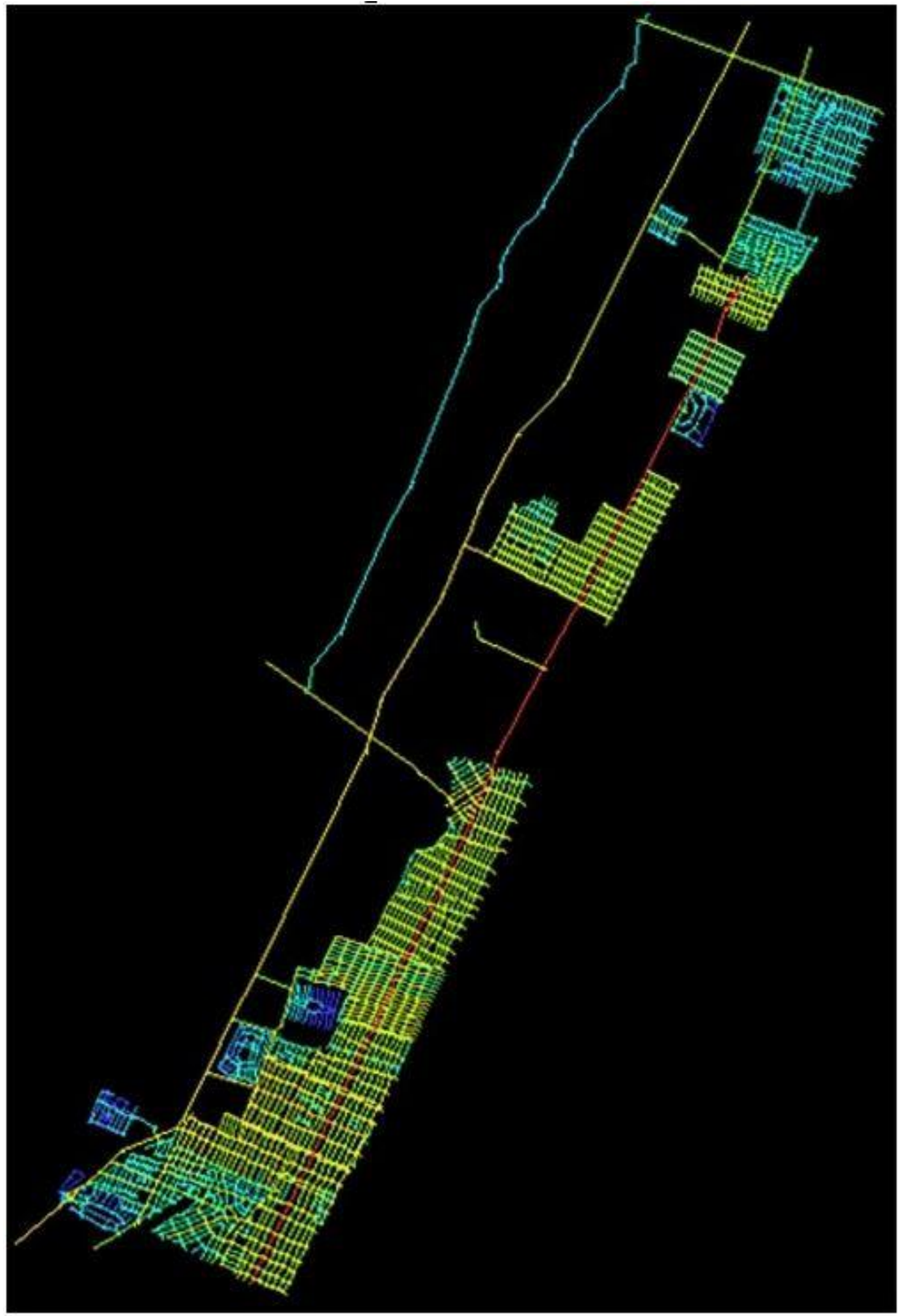

Figura 3 - Integração global (Rn) da cidade de Capão da Canoa. Fonte: Autores (2017). 


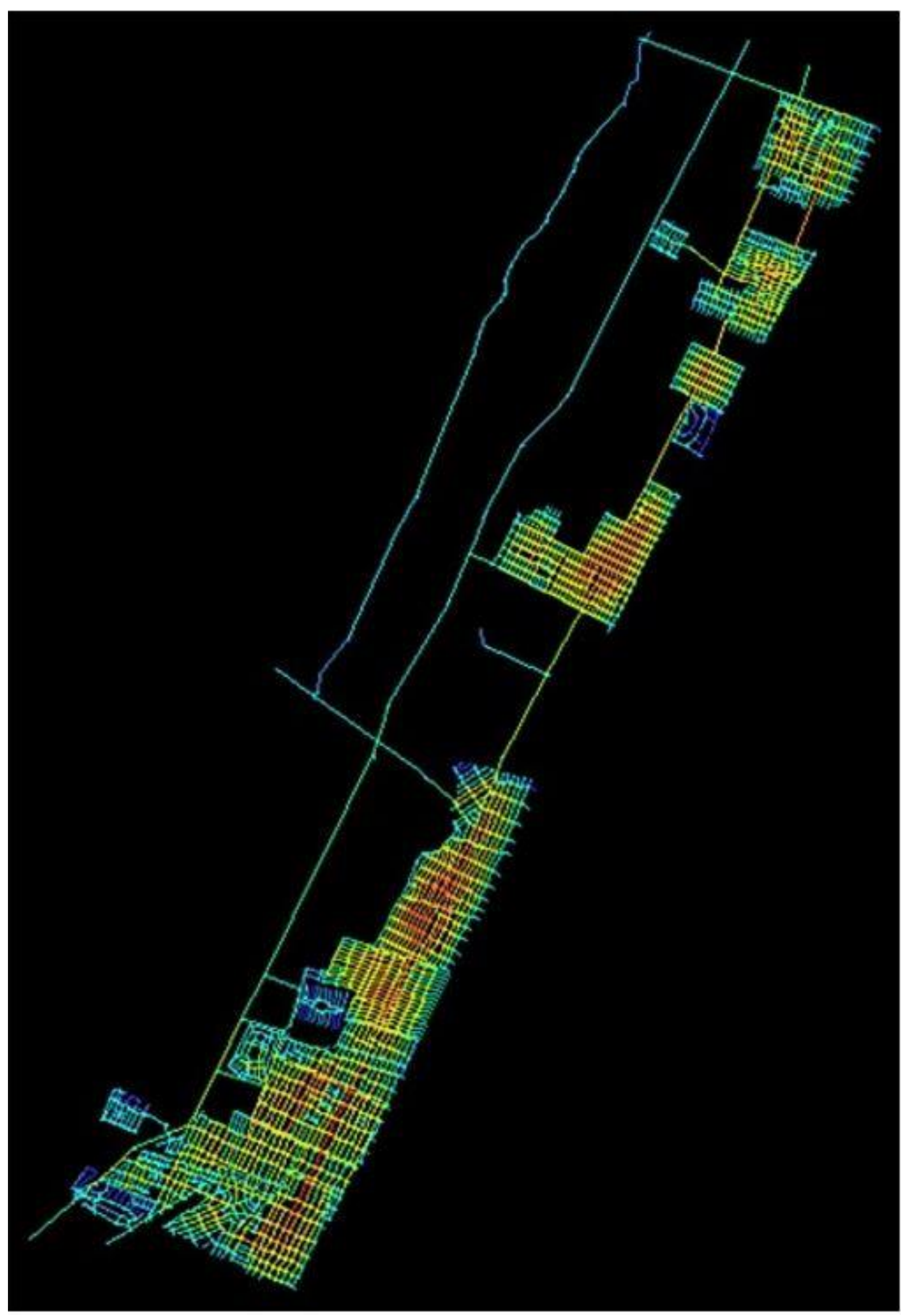

Figura 4 - Integração local (R5) da cidade de Capão da Canoa. Fonte: Autores (2017). 


\section{Metodologia}

Este estudo é limitado à cidade de Capão da Canoa (Figura 5), localizada no litoral norte do Rio Grande do Sul. A cidade possui uma população fixa de 47.148 moradores, podendo chegar a uma população flutuante de 200 mil usuários nos meses de verão (Atlas Brasil, 2013), como outras cidades litorâneas de pequeno porte voltadas mais para o turismo, utilizadas como segunda residência e com mais ocupação apenas em períodos de veraneio (Espínola, 2013). O município vem vivenciando transformações morfológicas, incluindo a substituição de edificações com térreos de usos residencial e comercial, constituídos por portas e janelas voltadas para a rua, por edifícios com predominância de portas de garagem e paredes cegas (sem aberturas) nos pavimentos térreos.

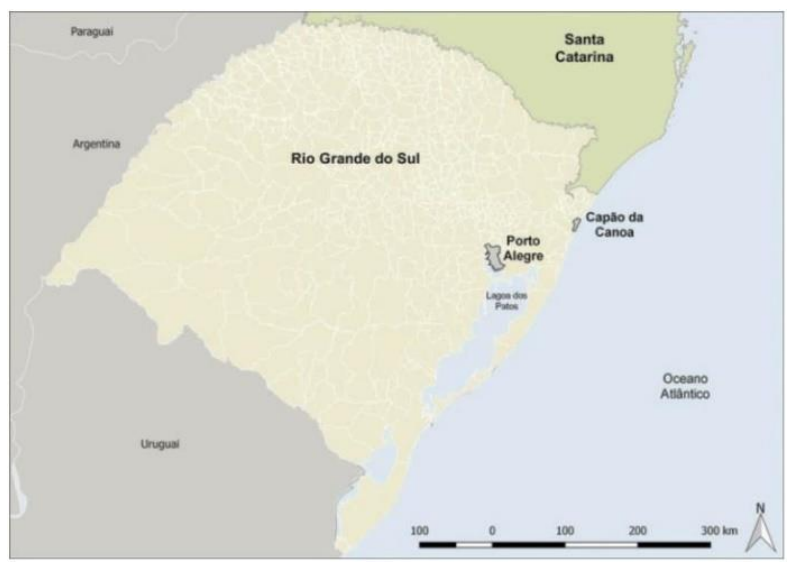

Figura 5 - Localização da cidade de Capão da Canoa. Fonte: Autores (2017).

Para atender ao objetivo deste trabalho, foram selecionadas, na área central do distrito sede de Capão da Canoa, onde as maiores transformações urbanas estão ocorrendo, nove quadras (Figura 6) categorizadas em três tipos conforme a predominância das seguintes características: (tipo 1) predomínio de edificações residenciais com térreos com portas e janelas voltadas para a rua; (tipo 2) predomínio de edificações residenciais com comércios e serviços nos térreos; (tipo 3) predomínio de edificações residenciais com portas de garagem e paredes cegas nos térreos.

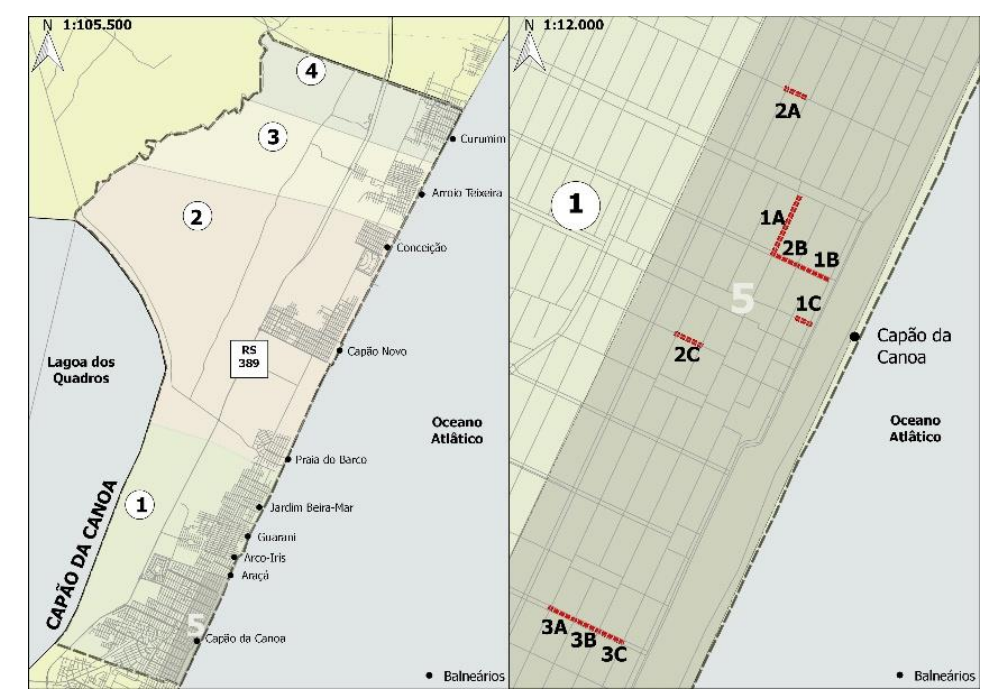

Figura 6 - Localização das nove quadras selecionadas. Linha tracejada = cidade de Capão da Canoa; $(1)=1^{\circ}$ Distrito Capão da Canoa; (2) = $2^{\circ}$ Distrito - Capão Novo; (3) = $3^{\circ}$ Distrito - Arroio Teixeira; (4) $=4^{\circ}$ Distrito - Curumim; (5) Área mais urbanizada do Município e área de estudo; $1 \mathrm{~A} / 1 \mathrm{~B} / 1 \mathrm{C}=$ quadras com térreos residenciais com portas e janelas voltadas para a rua; $2 \mathrm{~A} / 2 \mathrm{~B} / 2 \mathrm{C}=$ quadras com edifícios residenciais com comércios e serviços nos pavimentos térreos; $3 \mathrm{~A} / 3 \mathrm{~B} / 3 \mathrm{C}=$ quadras com edifícios com garagens e paredes cegas nos pavimentos térreos. Fonte: Autores (2017). 
O levantamento físico das nove quadras foi realizado considerando a quantificação das seguintes variáveis: permeabilidade visual (comprimento das transparências possibilitadas por janelas e portas de vidro); permeabilidade funcional (número de portas de acesso a pedestres); portas de garagem (comprimento horizontal); tipos de usos dos pavimentos térreos (residencial, garagem, comércios e serviços ou misto); tipos de usos dos recuos frontais (espaços de estar, estacionamento, ornamental, sem uso ou sem recuo); tamanho dos recuos frontais (até 3,50 metros, de 3,51 a 7,00 metros e acima de 7,00 metros). Essas medidas foram transformadas em taxas por meio da divisão da soma das medidas de cada variável nos dois lados das quadras pelo dobro do comprimento da quadra, multiplicado por 100 para representar a quantificação de cada variável em 100 metros.

A coleta de dados foi realizada mediante a aplicação de questionários e de entrevistas estruturadas in loco com usuários que moram, veraneiam (utilizam apartamentos alugados ou de propriedade, principalmente, durante os meses de veraneio - janeiro e fevereiro) ou trabalham nos três tipos de quadras investigadas nos dias 5 e 9 de novembro de 2016 e por meio de contagens do movimento de pedestres e de veículos nessas quadras. A amostra final do questionário foi constituída por 40 respondentes, sendo 25\% (10 de 40) usuários das quadras do tipo 1, 42,5\% (17 de 40) usuários das quadras do tipo 2 e 32,5\% (13 de 40) usuários das quadras do tipo 3 (Tabela 1).

Tabela 1 - Caracterização da amostra de respondentes dos questionários

\begin{tabular}{|c|c|c|c|c|c|c|c|c|c|c|c|c|}
\hline \multirow{2}{*}{ Respondentes } & \multicolumn{4}{|c|}{ Quadras tipo 1} & \multicolumn{4}{|c|}{ Quadras tipo 2} & \multicolumn{4}{|c|}{ Quadras tipo 3} \\
\hline & $\bar{A}$ & B & C & Total & $\bar{A}$ & B & $\mathrm{C}$ & Total & $\bar{A}$ & $\bar{B}$ & $\bar{C}$ & Total \\
\hline Morador & 5 & 1 & - & 6 & 1 & 4 & 1 & 6 & 1 & - & - & 1 \\
\hline Veranista proprietário & 2 & 1 & - & 3 & - & - & 2 & 2 & 3 & 5 & 2 & 10 \\
\hline Trabalhador & - & 1 & - & 1 & 2 & 2 & 5 & 9 & - & 1 & 1 & 2 \\
\hline Total (40) & 7 & 3 & - & 10 & 3 & 6 & 8 & 17 & 4 & 6 & 3 & 13 \\
\hline
\end{tabular}

Quadras tipo 1 = predomínio de térreos residenciais com portas e janelas voltadas para a rua; Quadras tipo 2 = predomínio de térreos com comércios e serviços; Quadras tipo 3 = predomínio de térreos com portas de garagem e paredes cegas. Fonte: Autores (2017).

O questionário foi composto de questões fechadas de escolha simples a respeito do uso das quadras durante o dia e à noite e questões abertas sobre os motivos para os usuários utilizarem ou não esses espaços e as atividades realizadas. Ainda, foram incluídas questões de escolha simples e de múltipla escolha relacionadas a dois conjuntos com cenas, cada um com os três tipos de quadras com as distintas interfaces consideradas (Figura 7), sobre as cenas mais e menos preferidas em relação à percepção de segurança quanto a crimes e acerca das justificativas para tais preferências, já que a percepção de segurança afeta o uso dos espaços urbanos, com espaços urbanos percebidos como menos seguros sendo menos utilizados, mesmo que não existam ou que existam poucos crimes neles (Vieira, 2002).

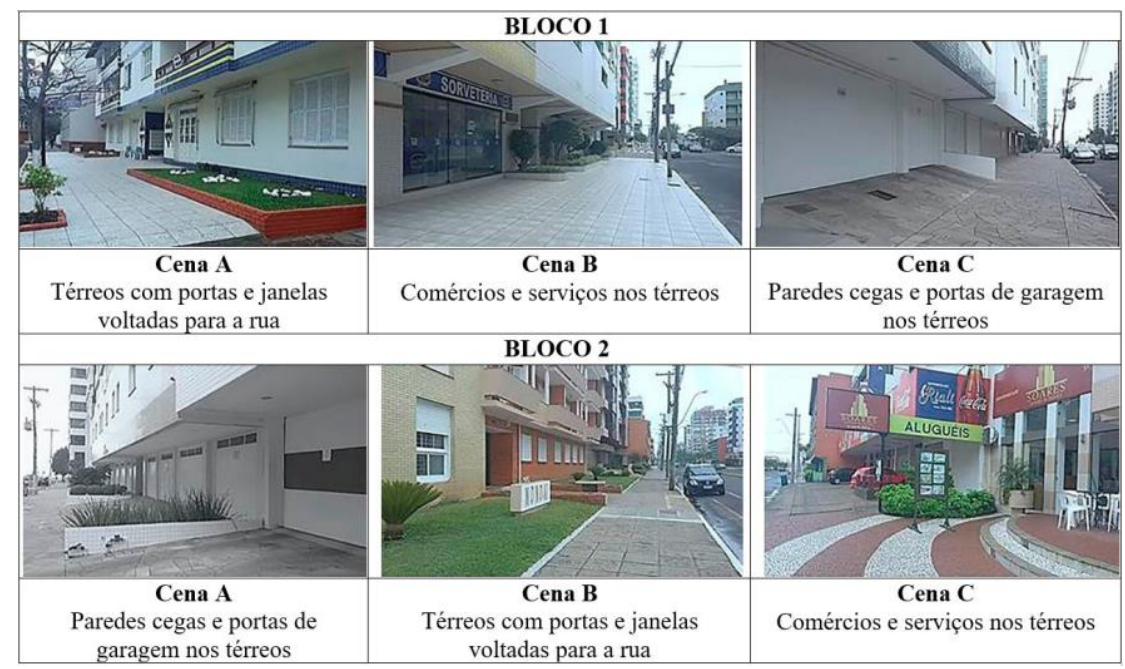

Figura 7 - Conjuntos com os três tipos de cenas avaliadas acerca da preferência em relação à percepção de segurança quanto a crimes. Fonte: Autores (2017). 
Adicionalmente, foram utilizadas perguntas abertas acerca da ocorrência, da quantidade e do turno de algum tipo de crime na quadra utilizada pelo respondente. A utilização de ocorrências criminais em determinadas áreas reportadas pelos próprios usuários de tais áreas tem ocorrido em outros estudos (p. ex., Vieira, 2002; Reis \& Dittmar, 2009) como alternativa à dificuldade de se obter tais dados de órgãos governamentais, pelo fato de muitas pessoas não registrarem as ocorrências e em razão de muitos crimes nas ruas, registrados nas delegacias de polícia, não serem localizados no âmbito das quadras. Assim, embora dados de ocorrências criminais em Capão da Canoa tenham sido solicitados ao serviço de estatística da Divisão de Planejamento e Coordenação da Polícia Civil (Diplanco) do estado do Rio Grande do Sul, esta informou que muitas pessoas não reportam a ocorrência de crimes ou não indicam com precisão o endereço onde estes ocorreram. Adicionalmente, dados enviados pelo serviço de estatística da Diplanco não indicam a localização dos diferentes tipos de crimes em Capão da Canoa. Logo, a falta dessas informações impede a análise das relações entre tais crimes e os atributos físico-espaciais das quadras consideradas neste estudo. Portanto, para responder aos objetivos deste estudo, são consideradas somente as ocorrências criminais informadas pelos usuários das quadras selecionadas.

As entrevistas estruturadas foram aplicadas nos mesmos dias dos questionários com o objetivo de obter informações mais detalhadas sobre o uso e a percepção de segurança dos usuários das quadras analisadas. A amostra final foi constituída por 34 entrevistados (Tabela 2), conforme segue: $26,5 \%$ (9 de 34) nas quadras com edificações residenciais com predomínio de portas e janelas voltadas para a rua (tipo 1); 44,1\% (15 de 34) nas quadras com edificações com predomínio de comércios e serviços nos térreos (tipo 2); 29,4\% (10 de 34) entrevistados nas quadras com predomínio de edificações residenciais com portas de garagem e paredes cegas nos térreos (tipo 3). 0 tamanho das amostras de respondentes dos questionários e das entrevistas ficou limitado pelos seguintes aspectos: existência de habitações desocupadas (por não ser período de veraneio) nas nove quadras no período de coleta de dados, principalmente nas quadras do tipo 3; quantidade de moradores e veranistas que se disponibilizaram a responder ao questionário e a participar da entrevista após terem sidos contatados pessoalmente ou por cartas de apresentação deixadas nas caixas postais de todas as edificações residenciais existentes em cada uma das nove quadras.

Tabela 2 - Caracterização da amostra de entrevistas

\begin{tabular}{|c|c|c|c|c|c|c|c|c|c|c|c|c|}
\hline \multirow{2}{*}{ Entrevistados } & \multicolumn{4}{|c|}{ Quadras tipo 1} & \multicolumn{4}{|c|}{ Quadras tipo 2} & \multicolumn{4}{|c|}{ Quadras tipo 3} \\
\hline & $A$ & B & C & Total & A & B & $\mathrm{C}$ & Total & A & B & $\mathrm{C}$ & Total \\
\hline Morador & 5 & 1 & - & 6 & 1 & 3 & 1 & 5 & 1 & - & - & 1 \\
\hline Veranista proprietário & 1 & 1 & - & 2 & - & - & 1 & 1 & 3 & 4 & - & 7 \\
\hline Trabalhador & - & 1 & - & 1 & 2 & 2 & 5 & 9 & - & 1 & 1 & 2 \\
\hline Total (34) & 6 & 3 & - & 9 & 3 & 5 & 7 & 15 & 4 & 5 & 1 & 10 \\
\hline
\end{tabular}

Quadras tipo 1 = predomínio de térreos residenciais com portas e janelas voltadas para a rua; Quadra tipo 2 = predomínio de térreos com comércios e serviços; Quadras tipo 3 = predomínio de térreos com portas de garagem e paredes cegas. Fonte: Autores (2017).

O movimento de pedestres e veículos nas quadras foi registrado mediante contagens realizadas em três dias, em outubro de 2016, durante três períodos de dez minutos (entre $9 \mathrm{~h}$ e $11 \mathrm{~h} 30 \mathrm{~min}$; entre $14 \mathrm{~h}$ e 16h30 min; entre $19 \mathrm{~h}$ e $21 \mathrm{~h} 30 \mathrm{~min}$ ), com o objetivo de identificar a intensidade de movimento nos três turnos. Com base nessas contagens, foram calculadas as taxas de movimento, dividindo-se a média das contagens em cada uma das nove quadras da amostra nos períodos da manhã, da tarde e da noite (em três dias distintos) por duas vezes o comprimento de cada segmento de rua (em função dos dois lados do segmento), multiplicado por 100 .

O movimento de pedestres e veículos também foi identificado e avaliado pela análise angular do mapa de segmentos (equivalente a uma quadra) que representa o sistema espacial do distrito sede de Capão da Canoa, permitindo verificar se o movimento nos segmentos selecionados está relacionado às suas características morfológicas ou às suas características configuracionais, isto é, às suas localizações no referido sistema. Nessa análise foram eliminados os ângulos menores que $25^{\circ}$, pois não são percebidos como mudanças de direções na navegação urbana (Hillier et al., 2012). As seguintes medidas foram 
consideradas: integração global (Rn) (Figura 8), que indica o nível de acessibilidade de um segmento e o seu potencial de movimento em relação a todos os outros segmentos no sistema em análise; integração local (R5) (Figura 9), que indica o nível de acessibilidade de um segmento e o seu potencial de movimento em relação aos segmentos distantes até cinco passos de profundidade (Hillier \& Vaughan, 2007).

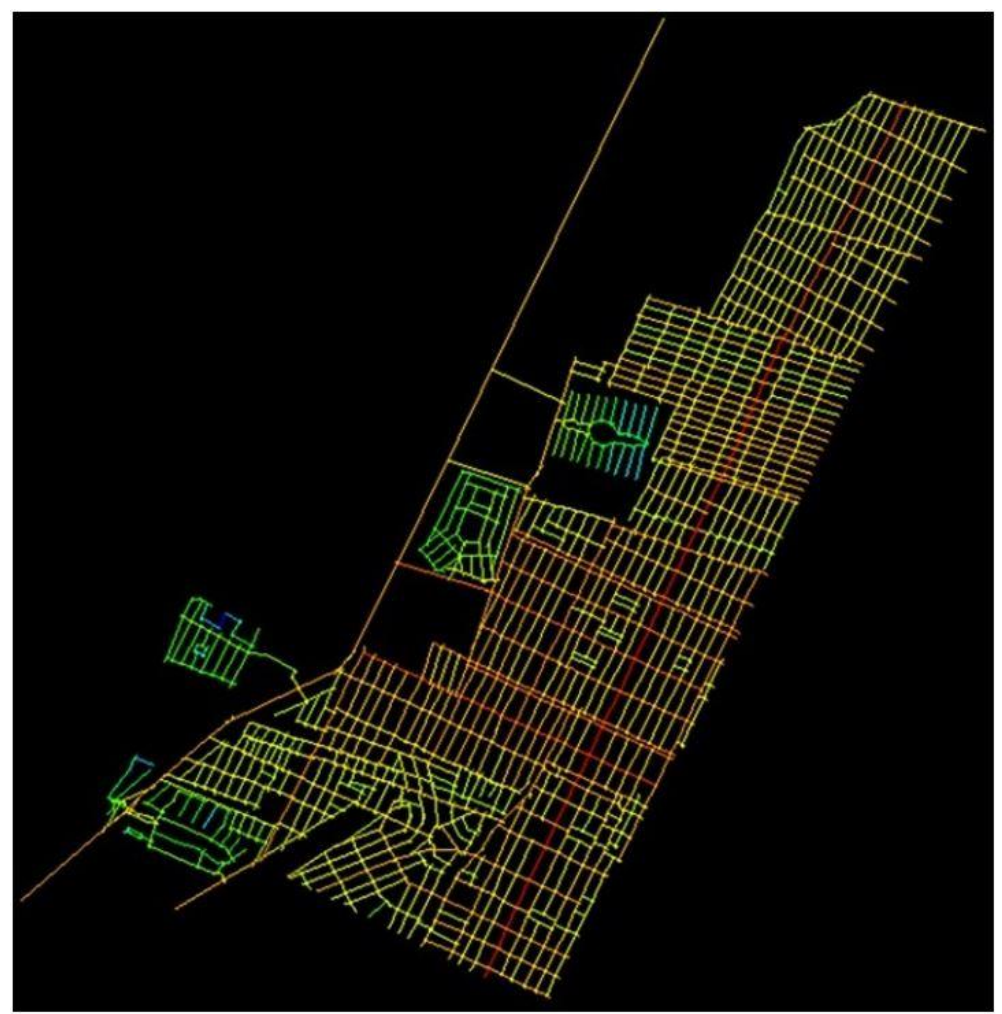

Figura 8 - Integração global (Rn) do distrito sede de Capão da Canoa. Fonte: Autores (2017).

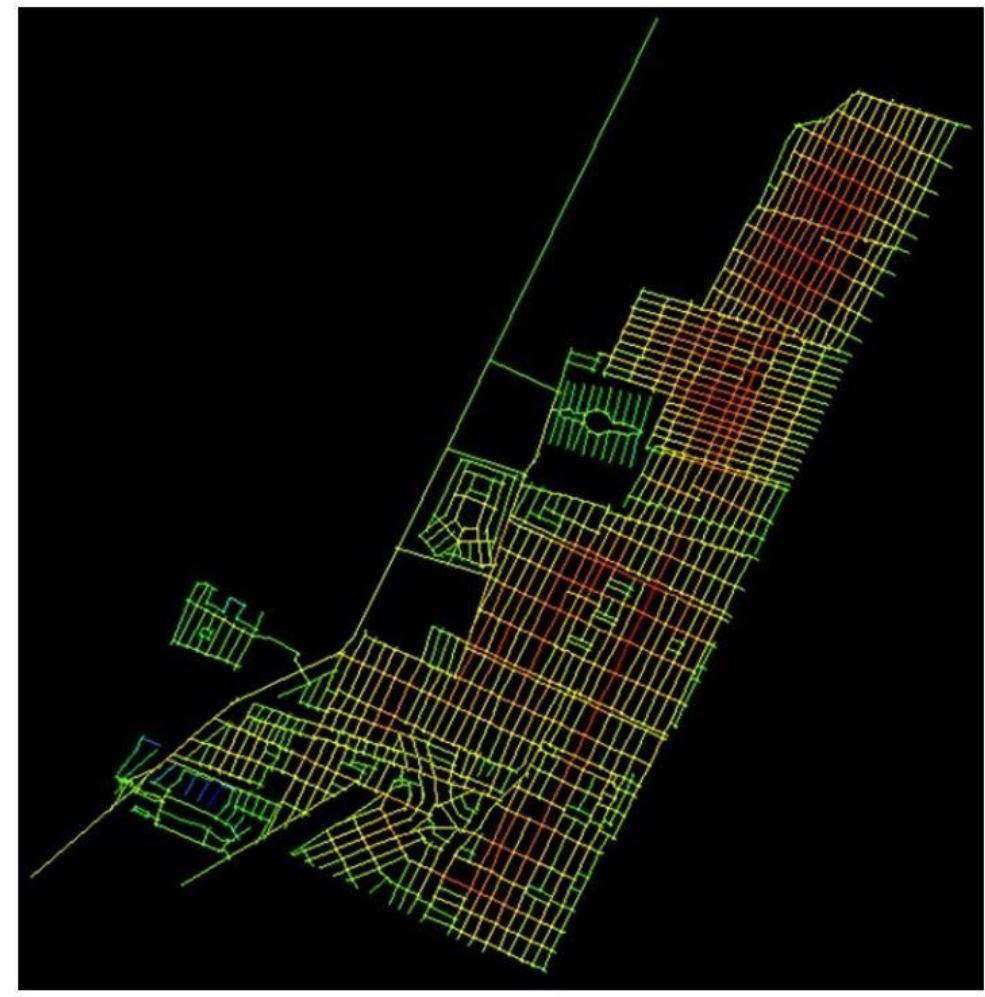

Figura 9 - Integração local (R5) do distrito sede de Capão da Canoa. Fonte: Autores (2017). 
Os dados provenientes dos questionários foram analisados no programa estatístico SPSS/PC por meio de frequências, testes estatísticos não paramétricos Kruskal-Wallis e Kendall's W e teste estatístico paramétrico de correlação Pearson. Os testes não paramétricos não assumem uma distribuição probabilística conhecida e permitem inferências independentemente das características ou da forma de distribuição da frequência dos dados (Siegel, 1975), possibilitando a realização de testes estatísticos com amostras de diferentes tamanhos de respondentes em cada um dos três tipos de quadras avaliados. Os testes são considerados estatisticamente significativos quando o valor de significância é igual ou inferior a 0,05 (sig. $\leq 0,05$ ) (Lay \& Reis, 2005). Os dados qualitativos das entrevistas estruturadas foram sintetizados e analisados por meio de suas frequências e significados, complementando a análise dos dados quantitativos.

\section{Resultados}

\section{Uso dos espaços abertos públicos nas quadras conforme os tipos de interfaces térreas das} edificações

As quadras do tipo $1(1 \mathrm{~A}, 1 \mathrm{~B}, 1 \mathrm{C})$ são utilizadas pela totalidade dos respondentes que moram (6), veraneiam (3) ou trabalham (1) nelas (10 de 10 - 100\%), em seus tempos livres, durante o dia. As quadras tipos 3 (3A, 3B e 3C) e 2 ( $2 \mathrm{~A}, 2 \mathrm{~B}$ e $2 \mathrm{C}$ ) também são muito utilizadas durante o dia, porém por um percentual um pouco menor de respondentes dessas quadras, respectivamente, 84,6\% (11 de 13) e $82,4 \%$ (14 de 17). Enquanto na quadra tipo 2 os moradores (6) e veranistas (2) a utilizam em seus tempos livres durante o dia, 33\% (3 de 9) daqueles que trabalham nesse tipo de quadra não a utilizam. Na quadra tipo 3, um veranista (de 10) e uma das duas pessoas que trabalham nesse tipo de quadra não a utilizam em seus tempos livres durante o dia (Tabela 3). Logo, o fato de a quadra 2 ser um pouco menos utilizada do que as outras duas explica-se pelo fato de três pessoas que trabalham nesse tipo de quadra não a utilizarem em seus tempos livres, enquanto todos aqueles que moram (6) ou veraneiam (2) nesse tipo de quadra a utilizam em seus tempos livres durante o dia, como acontece nas quadras tipo 1.

Tabela 3 - Identificação do uso das quadras pelos respondentes no tempo livre

\begin{tabular}{|c|c|c|c|c|c|c|c|c|c|c|c|c|}
\hline \multicolumn{13}{|c|}{ Uso das quadras durante o dia } \\
\hline & \multicolumn{4}{|c|}{ Quadras tipo 1} & \multicolumn{4}{|c|}{ Quadras tipo 2} & \multicolumn{4}{|c|}{ Quadras tipo 3} \\
\hline & $M$ & $\mathbf{V}$ & $T$ & Total & $M$ & V & $T$ & Total & $M$ & V & $T$ & Total \\
\hline Sim & $\begin{array}{c}6 \\
(100)\end{array}$ & $\begin{array}{c}3 \\
(100)\end{array}$ & $\begin{array}{c}1 \\
(100)\end{array}$ & $\begin{array}{c}10 \\
(100)\end{array}$ & $\begin{array}{c}6 \\
(100)\end{array}$ & $\begin{array}{c}2 \\
(100)\end{array}$ & $\begin{array}{c}6 \\
(66,67)\end{array}$ & $\begin{array}{c}14 \\
(82,35)\end{array}$ & $\begin{array}{c}1 \\
(100)\end{array}$ & $\begin{array}{c}9 \\
(90)\end{array}$ & $\begin{array}{c}1 \\
(50)\end{array}$ & $\begin{array}{c}11 \\
(84,62\end{array}$ \\
\hline Não & $\begin{array}{c}0 \\
(0)\end{array}$ & $\begin{array}{c}0 \\
(0)\end{array}$ & $\begin{array}{c}0 \\
(0)\end{array}$ & $\begin{array}{c}0 \\
\text { (0) }\end{array}$ & $\begin{array}{c}0 \\
(0)\end{array}$ & $\begin{array}{c}0 \\
(0)\end{array}$ & $\begin{array}{c}3 \\
(33,33)\end{array}$ & $\begin{array}{c}3 \\
(17,65)\end{array}$ & $\begin{array}{c}0 \\
(0)\end{array}$ & $\begin{array}{c}1 \\
(10)\end{array}$ & $\begin{array}{c}1 \\
(50)\end{array}$ & $\begin{array}{c}2 \\
(15,38\end{array}$ \\
\hline Total & $\begin{array}{c}6 \\
(100)\end{array}$ & $\begin{array}{c}3 \\
(100) \\
\end{array}$ & $\begin{array}{c}1 \\
(100) \\
\end{array}$ & $\begin{array}{c}10 \\
(100) \\
\end{array}$ & $\begin{array}{c}6 \\
(100) \\
\end{array}$ & $\begin{array}{c}2 \\
(100) \\
\end{array}$ & $\begin{array}{c}9 \\
(100)\end{array}$ & $\begin{array}{c}17 \\
(100) \\
\end{array}$ & $\begin{array}{c}1 \\
(100) \\
\end{array}$ & $\begin{array}{c}10 \\
(100) \\
\end{array}$ & $\begin{array}{c}2 \\
(100) \\
\end{array}$ & $\begin{array}{c}13 \\
(100) \\
\end{array}$ \\
\hline \multicolumn{13}{|c|}{ Uso das quadras durante a noite } \\
\hline & \multicolumn{4}{|c|}{ Quadras tipo 1} & \multicolumn{4}{|c|}{ Quadras tipo 2} & \multicolumn{4}{|c|}{ Quadras tipo 3} \\
\hline & $M$ & V & $T$ & Total & $M$ & V & $T$ & Total & $M$ & V & $T$ & Total \\
\hline Sim & $\begin{array}{c}0 \\
(0)\end{array}$ & $\begin{array}{c}2 \\
(66,67)\end{array}$ & $\begin{array}{c}0 \\
(0)\end{array}$ & $\begin{array}{c}2 \\
(20)\end{array}$ & $\begin{array}{c}4 \\
(66,67)\end{array}$ & $\begin{array}{c}2 \\
(100)\end{array}$ & $\begin{array}{c}1 \\
(11,11)\end{array}$ & $\begin{array}{c}7 \\
(41,18)\end{array}$ & $\begin{array}{c}1 \\
(100)\end{array}$ & $\begin{array}{c}6 \\
(60)\end{array}$ & $\begin{array}{c}1 \\
(50)\end{array}$ & $\begin{array}{c}8 \\
161,54\end{array}$ \\
\hline Não & $\begin{array}{c}6 \\
(100)\end{array}$ & $\begin{array}{c}1 \\
(33,3)\end{array}$ & $\begin{array}{c}1 \\
(100)\end{array}$ & $\begin{array}{c}8 \\
(80)\end{array}$ & $\begin{array}{c}2 \\
(33,3)\end{array}$ & $\begin{array}{c}0 \\
(0)\end{array}$ & $\begin{array}{c}8 \\
(88,89)\end{array}$ & $\begin{array}{c}10 \\
(58,82)\end{array}$ & $\begin{array}{c}0 \\
\text { (0) }\end{array}$ & $\begin{array}{c}4 \\
(40)\end{array}$ & $\begin{array}{l}1 \\
(50)\end{array}$ & $\begin{array}{c}5 \\
(38,46\end{array}$ \\
\hline Total & $\begin{array}{c}6 \\
(100)\end{array}$ & $\begin{array}{c}3 \\
(100)\end{array}$ & $\begin{array}{c}1 \\
(100)\end{array}$ & $\begin{array}{c}10 \\
(100)\end{array}$ & $\begin{array}{c}6 \\
(100)\end{array}$ & $\begin{array}{c}2 \\
(100)\end{array}$ & $\begin{array}{c}9 \\
(100)\end{array}$ & $\begin{array}{c}17 \\
(100)\end{array}$ & $\begin{array}{c}1 \\
(100)\end{array}$ & $\begin{array}{c}10 \\
(100)\end{array}$ & $\begin{array}{c}2 \\
(100)\end{array}$ & $\begin{array}{c}13 \\
(100)\end{array}$ \\
\hline
\end{tabular}

Quadras tipo 1 = predomínio de térreos residenciais com portas e janelas voltadas para a rua; Quadras tipo 2 = predomínio de térreos com comércios e serviços; Quadras tipo 3 = predomínio de térreos com portas de garagem e paredes cegas; $M=$ morador; $V=$ veranista; $\mathrm{T}$ = trabalhador; os valores entre parênteses referem-se aos percentuais em relação aos tipos de respondentes em cada quadra e a amostra total de respondentes que utiliza ou não as quadras avaliadas durante o dia e a noite. Fonte: Autores (2017). 
As principais atividades realizadas nas quadras tipo 1 durante o dia estão relacionadas à circulação (caminhadas - 70\%) e a atividades estacionárias (tomar chimarrão - 30\%; sentar na frente do edifício $30 \%$; cuidar das crianças enquanto brincam - 20\%). Nas quadras tipo 3, destacam-se caminhada $(81,8 \%)$ e atividades estacionárias (tomar chimarrão - 27,3\%; conversar com os vizinhos - 27,3\%), e nas quadras tipo 2, destaca-se caminhada (50\%) (Tabela 4). Corroborando esses resultados, um dos entrevistados da quadra " $2 \mathrm{C}$ ", por exemplo, menciona a preferência por se locomover a pé e a perda do hábito de andar de carro para realizar atividades cotidianas, como ir ao supermercado.

Tabela 4 - Identificação dos tipos de atividades realizados nas quadras

\begin{tabular}{|c|c|c|c|c|}
\hline Atividades realizadas durante o dia & $\begin{array}{l}\text { Quadras do tipo } 1 \\
10(100)\end{array}$ & $\begin{array}{c}\text { Quadra do tipo } 2 \\
14(100)\end{array}$ & $\begin{array}{c}\text { Quadras do tipo } 3 \\
11(100)\end{array}$ & $\begin{array}{c}\text { Total } \\
35(100)\end{array}$ \\
\hline Caminhar & $7(70)$ & $7(50)$ & $9(81,8)$ & $23(65,7)$ \\
\hline Tomar chimarrão & $3(30)$ & $2(14,2)$ & $3(27,3)$ & $8(22,9)$ \\
\hline Sentar na frente do edifício & $3(30)$ & $1(7,1)$ & $2(18,2)$ & $6(17,1)$ \\
\hline Cuidar das crianças enquanto brincam & $2(20)$ & $1(7,1)$ & $1(9,1)$ & $4(11,4)$ \\
\hline Conversar com os vizinhos & $1(10)$ & $1(7,1)$ & $3(27,3)$ & $5(14,3)$ \\
\hline Passear com animal de estimação & $1(10)$ & $2(14,2)$ & $0(0)$ & $3(8,6)$ \\
\hline Andar de bicicleta & $1(10)$ & $1(7,1)$ & $1(9,1)$ & $3(8,6)$ \\
\hline Tomar banho de sol & $1(10)$ & $2(14,2)$ & $0(0)$ & $3(8,6)$ \\
\hline Olhar as vitrines das lojas & $0(0)$ & $1(7,1)$ & $0(0)$ & $1(2,9)$ \\
\hline Trabalhar & $0(0)$ & $1(7,1)$ & $0(0)$ & $1(2,9)$ \\
\hline Descansar & $0(0)$ & $0(0)$ & $1(9,1)$ & $1(2,9)$ \\
\hline Atividades realizadas durante a noite & $\begin{array}{c}\text { Quadras do tipo } 1 \\
2(100) \\
\end{array}$ & $\begin{array}{c}\text { Quadra do tipo } 2 \\
7(100) \\
\end{array}$ & $\begin{array}{c}\text { Quadras do tipo } 3 \\
8(100) \\
\end{array}$ & $\begin{array}{c}\text { Total } \\
17(100)\end{array}$ \\
\hline Caminhar & $1(50)$ & $6(85,7)$ & $5(62,5)$ & $12(70,6)$ \\
\hline Tomar chimarrão & $0(0)$ & $2(28,6)$ & $0(0)$ & $2(11,8)$ \\
\hline Sair para jantar & $0(0)$ & $0(0)$ & $2(25)$ & $2(11,8)$ \\
\hline Passear com animal de estimação & $0(0)$ & $1(14,3)$ & $1(12,5)$ & $2(11,8)$ \\
\hline Sentar na frente do edifício & $1(50)$ & $0(0)$ & $1(12,5)$ & $2(11,8)$ \\
\hline Olhar as vitrines das lojas & $0(0)$ & $1(14,3)$ & $0(0)$ & $1(5,9)$ \\
\hline Assistir a shows na rua & $1(50)$ & $0(0)$ & $0(0)$ & $1(5,9)$ \\
\hline Trabalhar & $0(0)$ & $1(14,3)$ & $0(0)$ & $1(5,9)$ \\
\hline Conversar com os vizinhos & $0(0)$ & $0(0)$ & $1(12,5)$ & $1(5,9)$ \\
\hline
\end{tabular}

Quadras tipo 1 = predomínio de térreos residenciais com portas e janelas voltadas para a rua; Quadras tipo 2 = predomínio de térreos com comércios e serviços; Quadras tipo 3 = predomínio de térreos com portas de garagem e paredes cegas; os tipos de atividades listados foram especificados para classificar as atividades mencionadas pelos respondentes; os valores entre parênteses referem-se aos percentuais em relação às atividades realizadas durante o dia e durante a noite pelos respondentes de cada quadra e pelo total de respondentes. Fonte: Autores (2017).

O uso das quadras tipos 1 e 2 pelos respondentes que moram, veraneiam ou trabalham em cada um desses dois tipos de quadra em seus tempos livres durante a noite (respectivamente, $20 \%-2$ de 10, e 41,2\% - 7 de 17) diminui substancialmente em relação aos seus usos durante o dia. 0 uso das quadras tipo 3 durante a noite também diminui $(61,5 \%$ - 8 de 13$)$, mas de forma menos intensa. Contudo, no caso das quadras tipo 2, 8 dos 17 (47\%) respondentes trabalham nela (5 - das $8 \mathrm{~h}$ às $19 \mathrm{~h} ; 3$ - das $8 \mathrm{~h}$ às $20 \mathrm{~h}$ ) e não realizam atividades nesse tipo de quadra durante a noite, principalmente por razões relacionadas à própria atividade de trabalhar na quadra, nomeadamente: "não tem tempo livre" - 2 (25\%); "só trabalha na quadra" - 2 (25\%); "chega do trabalho muito cansado" - 1 (12,5\%). Adicionalmente, considerando apenas os moradores e os veranistas (aqueles que possuem mais vivência da quadra e disponibilidade de tempo livre para sua utilização), verifica-se que a quadra 2 (com comércio e serviços no térreo) é a mais utilizada durante à noite (75\% - 6 de 8), seguida das quadra $3(63,64 \%$ - 7 de 11$)$ e da $1(22,22 \%$ - 2 de 9$)$ (Tabela 3). 0 fato de as quadras tipo 3 serem mais utilizadas por moradores e veranistas durante a noite do que as quadras tipo 1 explica-se, principalmente, por aspectos relacionados à segurança (Tabela 5), detalhados mais adiante neste artigo. 
Tabela 5 - Principais razões dos respondentes para não utilizar as quadras

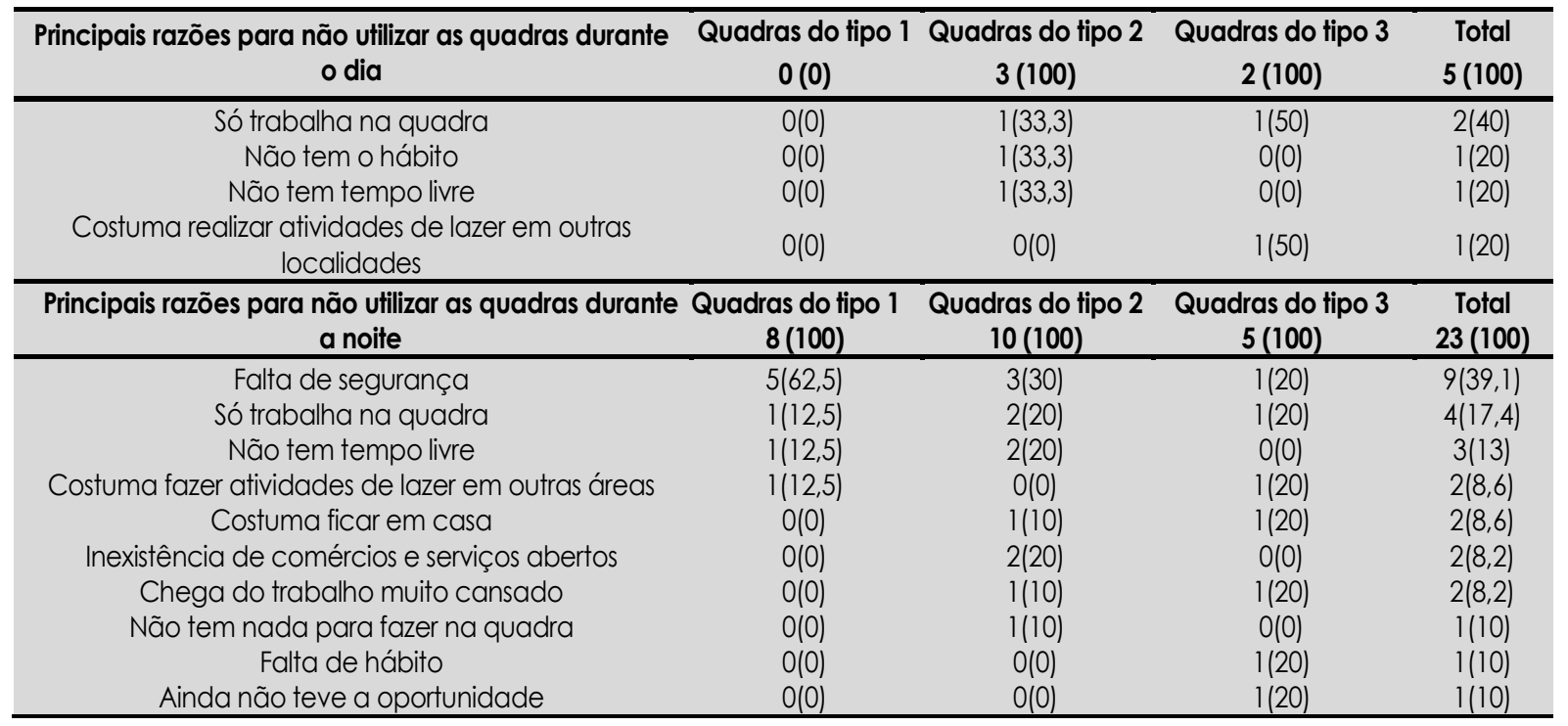

Quadras tipo 1 = predomínio de térreos residenciais com portas e janelas voltadas para a rua; Quadras tipo 2 = predomínio de térreos com comércios e serviços; Quadras tipo 3 = predomínio de térreos com portas de garagem e paredes cegas; os tipos de razões listados foram especificados para classificar as razões mencionadas pelos respondentes; os valores entre parênteses referem-se aos percentuais em relação às razões dos respondentes da amostra total e de cada tipo de quadra para não utilizar o espaço público das quadras avaliadas durante o dia e a noite. Fonte: Autores (2017).

Durante a noite, nas quadras tipo 2 , destacam-se caminhada (85,7\%) e a atividade de tomar chimarrão (28,6\%); nas quadras tipo 3, destaca-se caminhada (62,5\%) e sair para jantar (25\%); na quadra tipo 1 , um dos respondentes costuma caminhar (50\%) e outro costuma sentar na frente do edifício (50\%) e assistir a shows na rua (50\%) (Tabela 4).

Em consonância com os resultados anteriores que revelam que as quadras tipo 2 são utilizadas nos tempos livres durante o dia pela totalidade dos respondentes que moram ou veraneiam nela, as taxas de movimento de pedestres durante o dia (manhã e tarde) nas quadras 2 são, claramente, as mais altas, enquanto as mais baixas estão nas quadras tipo 3 (Tabela 6). Contudo, além das características específicas da quadra em termos de permeabilidade visual e usos no térreo, o movimento também é determinado pelas características de acessibilidade da quadra. Por exemplo, a quadra tipo $1 \mathrm{C}$ possui a maior taxa de movimento de pedestres durante a tarde $(37,18)$ e a segunda maior $(26,98)$ no turno da manhã, em razão de sua proximidade da praia e do centro da cidade e de servir como rota para seus frequentadores (Figura 4).

Tabela 6 - Taxas de movimento de pedestres e veículos

\begin{tabular}{cccccc}
\hline \multirow{2}{*}{ Tipos de quadras } & & \multicolumn{3}{c}{ Taxas de movimento de pedestres } \\
\cline { 3 - 5 } & & Manhã & Tarde & Noite & Média geral \\
\hline Tipo 1 & $\mathrm{A}$ & 5,10 & 5,02 & 5,18 & 5,10 \\
Predomínio de térreos residenciais & $\mathrm{B}$ & 14,24 & 13,86 & 11,04 & 13,04 \\
com portas e janelas voltadas & $\mathrm{C}$ & 26,98 & 37,18 & 23,81 & 29,32 \\
para a rua & Médias & 15,44 & 18,69 & 13,34 & 15,82 \\
\hline Tipo 2 & $\mathrm{A}$ & 17,84 & 16,75 & 22,62 & 19,07 \\
Predomínio de térreos com & $\mathrm{B}$ & 22,08 & 18,83 & 34,49 & 25,13 \\
comércios e serviços & $\mathrm{C}$ & 18,14 & 44,14 & 32,83 & 31,70 \\
\hline Tipo 3 & Médias & 19,35 & 26,57 & 29,98 & 25,30 \\
\hline Predomínio de térreos com portas & $\mathrm{A}$ & 11,52 & 11,04 & 9,66 & 10,74 \\
de garagem e paredes cegas & $\mathrm{B}$ & 12,39 & 13,08 & 11,91 & 12,46 \\
\hline
\end{tabular}


Tabela 6 - Continuacão...

\begin{tabular}{cccccc}
\hline Tipos de quadras & & \multicolumn{4}{c}{ Taxas de movimento de veículos } \\
\cline { 3 - 6 } & & Manhã & Tarde & Noite & Média geral \\
\hline Tipo 1 & $\mathrm{A}$ & 4,75 & 3,49 & 8,59 & 5,61 \\
Predomínio de térreos residenciais & $\mathrm{B}$ & 14,56 & 17,75 & 18,82 & 17,04 \\
com portas e janelas voltadas para & $\mathrm{C}$ & 13,25 & 27,80 & 25,33 & 22,13 \\
a rua & Médias & 10,85 & 16,35 & 17,58 & 14,93 \\
\hline Tipo 2 & $\mathrm{A}$ & 12,31 & 10,64 & 12,56 & 11,84 \\
Predomínio de térreos com & $\mathrm{B}$ & 32,42 & 24,83 & 36,77 & 31,34 \\
comércios e serviços & $\mathrm{C}$ & 6,69 & 3,86 & 19,03 & 11,86 \\
\hline Tipo 3 & Médias & 17,14 & 15,11 & 22,79 & 18,35 \\
\hline Predomínio de térreos com portas & $\mathrm{A}$ & 28,98 & 39,81 & 37,05 & 35,28 \\
de garagem e paredes cegas & $\mathrm{B}$ & 30,08 & 38,55 & 31,87 & 33,50 \\
& $\mathrm{C}$ & 21,91 & 36,85 & 29,24 & 29,33 \\
\hline As & Médias & 26,99 & 38,40 & 32,72 & 32,70 \\
\hline
\end{tabular}

As letras $(\mathrm{A}, \mathrm{B}$ e C) se referem às três quadras em cada um dos três tipos; as taxas são calculadas pela média das contagens em cada uma das nove quadras da amostra (em três dias distintos durante os períodos da manhã, da tarde e da noite) divididas por duas vezes o comprimento de cada segmento de rua (ou quadra) e multiplicado por 100. Fonte: Autores (2017).

Ainda, a taxa de movimento de pedestres durante a noite nas quadras tipo 2 é quase o triplo da taxa nas quadras tipo 3 e um pouco mais que o dobro da taxa nas quadras tipo 1, embora as quadras tipo 3 apresentem $o$ segundo maior percentual de usuários durante a noite que moram ou veraneiam nesse tipo de quadra (Tabelas 3 e 6). Um dos entrevistados na quadra tipo 2C destacou que gosta de ficar na rua em frente ao seu edifício até mais tarde, para observar o movimento de pedestres, principalmente durante o verão, quando esse movimento cresce com a presença de veranistas.

Portanto, as taxas de movimento de pedestres durante a manhã, tarde e noite tendem a ser maiores nas quadras tipo 2 e menores nas quadras tipo 3, o que é corroborado pela maior taxa de conexões visuais e de quantidade de portas de acesso às edificações nas quadras tipos 2 e menor nas quadras tipo 3 . Embora não tenham sido encontradas correlações (Pearson) entre as taxas de permeabilidade visual, assim como entre as taxas de número de acessos e as taxas de movimento de pedestres em nenhum dos três tipos de quadras em cada um dos três turnos, foi verificada correlação entre a taxa de permeabilidade visual e a taxa de movimento de pedestres no turno da noite (coeficiente de Pearson = 0,734; sig. $=0,024$ ) quando consideradas as nove quadras juntas.

Por sua vez, as menores taxas de movimento de pedestres nas quadras tipo 3 são corroboradas pelo fato de esse tipo de quadra apresentar a maior taxa de portas de garagem $(31,13)$, quase o dobro do que nos outros dois tipos de quadras (tipo 2 - 17,45; tipo 1 - 17,55) (Tabela 7). Tais resultados são corroborados pelas correlações (negativas) nas quadras tipo 1 entre as taxas de movimento de pedestres e as taxas de portas de garagem nos turnos da manhã (coeficiente de Pearson $=-0,998$; sig. $=0,039$ ) e da noite (coeficiente de Pearson $=-0,998$; sig. $=0,035$ ), indicando que quanto maior a taxa de portas de garagem na quadra (segmento), menor a taxa de movimento de pedestres. Adicionalmente, foram encontradas correlações negativas entre as taxas de movimento de pedestres e as taxas de portas de garagem nos turnos da manhã (coeficiente de Pearson = - 0,688; sig. $=0,049$ ) e da tarde (coeficiente de Pearson $=-0,793$; sig. $=0,011$ ), quando consideradas as nove quadras.

Tabela 7 - Taxas de conexões físicas e visuais das interfaces térreas

\begin{tabular}{ccccc}
\hline Tipos de quadras & & Número de portas & Portas de garagem & Permeabilidade visual \\
\hline Tipo 1 & A & 13,47 & 32,18 & 41,37 \\
Predomínio de térreos residenciais com & B & 11,73 & 20,47 & 37,35 \\
portas e janelas voltadas para a rua & C & 1,17 & 0,00 & 41,29 \\
& Médias & 8,79 & 17,55 & 40,00 \\
\hline Tipo 2 & A & 12,56 & 21,44 & 37,78 \\
Predomínio de térreos com comércios e & B & 18,63 & 24,28 & 49,19 \\
serviços & C & 14,48 & 6,62 & 51,59 \\
Tipo 3 & Médias & 15,22 & 17,45 & 46,19 \\
\hline \multirow{2}{*}{ Predomínio de térreos com portas de } & A & 7,59 & 19,87 & 24,87 \\
garagem e paredes cegas & B & 8,95 & 44,77 & 25,47 \\
& Médias & 9,68 & 28,76 & 20,81 \\
\hline
\end{tabular}

As letras $(A, B$ e C $)$ se referem às três quadras em cada um dos três tipos; as taxas de conexões físicas e visuais correspondem à divisão do número de acesso aos edifícios pelo dobro do comprimento de cada quadra e multiplicado por 100. Fonte: Autores (2017). 
Adicionalmente, o fato de as taxas de movimento de pedestres durante a manhã, tarde e noite tenderem a ser maiores nas quadras tipo 2 é explicado pela taxa média muito maior de usos comerciais e serviços nesse tipo de quadra. Tais considerações são parcialmente suportadas pela existência de correlação entre taxas de movimento de pedestres e taxas de comércios e serviços no turno da noite (coeficiente de Pearson = 0,797; sig. $=0,010$ ), quando as nove quadras foram incluídas no teste de correlação. Salienta-se que as medições de movimento de pedestres durante a noite foram realizadas em um período (das 19 até as $21 \mathrm{~h} 30 \mathrm{~min}$ ) no qual muitas atividades comerciais e de serviços ainda estavam abertas. Por outro lado, a tendência de concentração das menores taxas de movimento de pedestres durante a manhã, tarde e noite nas quadras tipo 3 também é explicada pela bem menor taxa média de uso residencial nos térreos, assim como pela bem maior taxa média de portas de garagens nas três quadras tipo 3, em comparação aos outros dois tipos de quadra (Tabela 8).

Tabela 8 - Taxas dos tipos de usos nos pavimentos térreos

\begin{tabular}{cccccc}
\hline Tipos de quadras & Residencial & Garagem & $\begin{array}{c}\text { Comércios e } \\
\text { serviços }\end{array}$ & Uso misto \\
\hline Tipo 1 & $\mathrm{A}$ & 42,26 & 33,87 & 0,00 & 23,86 \\
predomínio de térreos & $\mathrm{B}$ & 48,32 & 30,19 & 0,00 & 21,48 \\
residenciais com portas e & $\mathrm{C}$ & 100,00 & 0,00 & 0,00 & 0,00 \\
janelas voltadas para a rua & Médias & 63,53 & 21,35 & 0,00 & 15,11 \\
\hline Tipo 2 & $\mathrm{A}$ & 25,14 & 12,19 & 37,80 & 24,86 \\
predomínio de térreos com & $\mathrm{B}$ & 10,40 & 10,18 & 19,12 & 60,29 \\
comércios e serviços & $\mathrm{C}$ & 29,65 & 18,96 & 39,65 & 11,72 \\
\hline Tipo 3 & Médias & 21,73 & 13,78 & 32,19 & 32,29 \\
predomínio de térreos com & $\mathrm{A}$ & 0,00 & 39,89 & 0,00 & 50,00 \\
portas de garagem e paredes & $\mathrm{B}$ & $\mathbf{9}, 11$ & 80,90 & 0,00 & 0,00 \\
cegas & $\mathrm{C}$ & 0,00 & 79,15 & 0,00 & 20,84 \\
\hline
\end{tabular}

As letras (A, B e C) se referem às três quadras em cada um dos três tipos; as taxas de usos dos pavimentos térreos correspondem à razão entre o número de acessos aos edifícios (classificados conforme os tipos de usos nos pavimentos térreos) divididos pelo dobro do comprimento de cada quadra e multiplicados por 100. Fonte: Autores (2017).

Com relação aos recuos frontais, foi encontrada somente uma correlação negativa (coeficiente de Pearson $=-0,713$, sig. $=0,031$ ) entre o uso dos recuos como acesso a garagens e as taxas de movimento de pedestres nas nove quadras no turno da tarde, indicando que nesse turno tal movimento nas quadras diminui conforme $o$ aumento de garagens nos térreos. Embora não tenham sido encontradas correlações entre as taxas de movimento de pedestres nas nove quadras e os usos dos recuos como espaços de estar e jardins, em qualquer um dos três turnos, as quadras do tipo 2 (que possuem as maiores taxas de movimento de pedestres em cada um dos três turnos) tendem a se caracterizar por percentuais maiores de áreas de estar nos recuos frontais, enquanto as quadras do tipo 3 tendem a se caracterizar por recuos utilizados como acesso às garagens ou como jardins (Tabela 9).

Tabela 9 - Caracterização dos tipos de usos dos recuos frontais

\begin{tabular}{|c|c|c|}
\hline Tipos de quadras & & Usos dos recuos frontais \\
\hline $\begin{array}{l}\text { Tipo } 1 \\
\text { Predomínio de edificações } \\
\text { residenciais, com portas e janelas } \\
\text { voltadas para a rua }\end{array}$ & $\begin{array}{l}\text { A } \\
\text { B } \\
\text { C } \\
\text { Média }\end{array}$ & $\begin{array}{l}53,8 \% \text {, jardins; } 23,1 \% \text {, áreas de estar; } 3,8 \% \text {, estacionamentos; } 19,2 \% \text {, acesso a garagens } \\
55,4 \% \text {, áreas de estar; } 28,6 \% \text {, acesso a garagens; } 16 \% \text {, jardins } \\
100 \% \text {, jardins } \\
56,6 \% \text {, jardins; } 26,7 \% \text {, áreas de estar; } 15,9 \% \text {, acesso a garagens; } 1,3 \% \text {, estacionamento }\end{array}$ \\
\hline $\begin{array}{l}\text { Tipo } 2 \\
\text { Predomínio de edificações } \\
\text { residenciais com comércios e } \\
\text { serviços nos térreos }\end{array}$ & $\begin{array}{l}\text { B } \\
\text { Média }\end{array}$ & 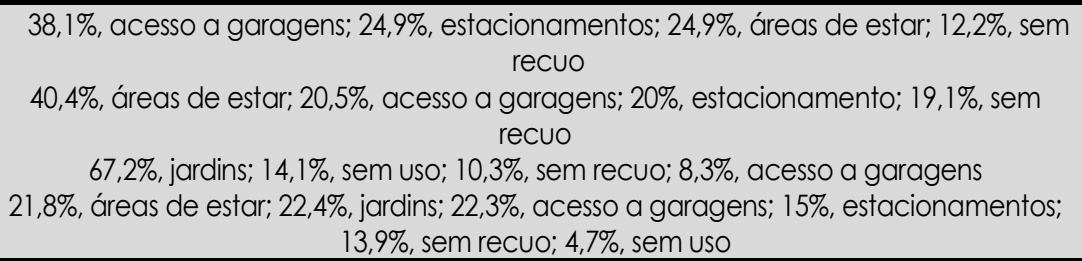 \\
\hline $\begin{array}{l}\text { Tipo } 3 \\
\text { Predomínio de edificações } \\
\text { residenciais com portas de } \\
\text { garagem e paredes sem }\end{array}$ & $\begin{array}{l}\text { A } \\
\text { B } \\
\text { C }\end{array}$ & $\begin{array}{l}50 \% \text {, acesso a garagens; } 50 \% \text {, jardins } \\
50 \% \text {, jardins; } 30 \% \text {, acesso a garagens; } 20 \% \text {, áreas de estar } \\
49,2 \% \text {, jardins; } 40,8 \% \text {, acesso a garagens; } 10 \% \text {, sem uso }\end{array}$ \\
\hline aberturas nos térr & Média & sso a garagens; $6,7 \%$, áreas de estar; 3,3 \\
\hline
\end{tabular}

Fonte: Autores (2017). 
Ainda, foi observado que as muradas de alguns jardins nos recuos frontais de lotes com comércios e serviços nos térreos das edificações das quadras tipo 2 são utilizadas como áreas de estar pelos usuários, enquanto nas quadras tipo 3, em que predominam acessos a garagens e paredes cegas nos térreos das edificações, a existência de jardins nos recuos frontais é apenas ornamental. Esse fato é corroborado pela existência de correlação (coeficiente de Pearson $=0,998$; sig. $=0,043$ ) entre a taxa de movimento de pedestres no turno da tarde nas quadras tipo 2 e a existência de jardins nos recuos frontais. Adicionalmente, a comparação entre os comprimentos dos recuos frontais nos três tipos de quadras revela que tais recuos tendem a ser um pouco menores nas quadras tipo 1 e um pouco maiores nas quadras tipo 2 (Tabela 10).

Tabela 10 - Comprimento dos recuos frontais

\begin{tabular}{|c|c|c|}
\hline Tipos de quadras & & Tamanhos dos recuos frontais \\
\hline $\begin{array}{c}\text { Tipo } 1 \\
\text { Predomínio de edificações residenciais, } \\
\text { com portas e janelas voltadas para a } \\
\text { rua }\end{array}$ & $\begin{array}{l}\text { A } \\
\text { B } \\
\text { C } \\
\text { Média }\end{array}$ & $\begin{array}{c}4,00 m-50 \% ; 3,00 m-39,2 \% ; 6,00 m-7,7 \% ; 5,00 m-3 \% \\
5,00 m-48,2 \% ; 4,00 m-35,8 \% ; 2,00 m-16 \% \\
3,00 m-50 \% ; 2,00 m-50 \% \\
3,00 m=29,7 \% ; 4,00 m-28,6 \% ; 2,00 m=22 \% ; 5,00 m=17 \% ; 6,00 m=2,6 \%\end{array}$ \\
\hline $\begin{array}{l}\text { Tipo } 2 \\
\text { Predomínio de edificações residenciais } \\
\text { com comércios e serviços nos térreos }\end{array}$ & $\begin{array}{l}\text { A } \\
\text { B } \\
\text { C } \\
\text { Média }\end{array}$ & $\begin{array}{c}4,00 m-63 \% ; 2,00 m-25 \% ; 0,00 m-12 \% \\
6,00 m-29,7 \% ; 4,00 m-20,5 \% ; 2,00 m=20,1 \% ; 0,00 m=19,1 \% ; 3,00 m=10,4 \% \\
4,00 m=57,6 \% ; 7,00 m=20 \% ; 2,00 m=14,1 \% ; 0,00 m=8,3 \% \\
4,00 m=47 \% ; 2,00 m=19,8 \% ; 0,00 m=13,1 \% ; 6,00 m=9,9 \% ; 7,00 m=6,7 \% ; 3,00 m=3,5 \%\end{array}$ \\
\hline $\begin{array}{c}\text { Tipo } 3 \\
\text { Predomínio de edificações residenciais } \\
\text { com portas de garagem e paredes } \\
\text { sem aberturas nos térreos }\end{array}$ & $\begin{array}{l}\text { A } \\
\text { B } \\
\text { Cédia }\end{array}$ & $\begin{array}{c}4,00 m=50 \% ; 2,00 m=50 \% \\
4,00 m=90,9 \% ; 9,50 m=9,1 \% \\
4,00 m=60 \% ; 2,00 m=40 \% \\
4,00 m=67 \% ; 2,00 m=30 \% ; 9,50 m=3 \%\end{array}$ \\
\hline
\end{tabular}

Fonte: Autores (2017).

Com relação aos níveis de integração dos segmentos, os resultados indicam que o segundo maior fluxo de pedestres (Tabela 6) é encontrado no segmento com menor integração global e local - quadra 1C (Tabela 11 e Figuras 10 e 11). Ainda, a quadra 3A, apesar de ser um dos segmentos de rua com maior integração local (R5), tem reduzido movimento de pedestres em relação às outras quadras analisadas (Tabela 11). Não foram encontradas correlações (Pearson) entre as taxas de movimento de pedestres e as medidas de integrações global e local por tipo de quadra e turno. Todavia, foi verificada correlação negativa entre (coeficiente de Pearson $=-0,709$; sig. $=0,032$ ) taxas de movimento de pedestres durante a tarde e medidas de integração global (Rn), quando consideradas as nove quadras, sem distinção de tipo de quadra. Esse resultado pode ser explicado pelo fato de os segmentos mais integrados globalmente (1B e 2B) estarem em avenidas mais largas e menos sombreadas, potencializando menos movimento de pedestres nas tardes ensolaradas e quentes do final de outubro e início de novembro (quando tais medições de movimento foram feitas) do que em segmentos menos integrados em vias mais estreitas e sombreadas (1C e $2 \mathrm{C})$. 


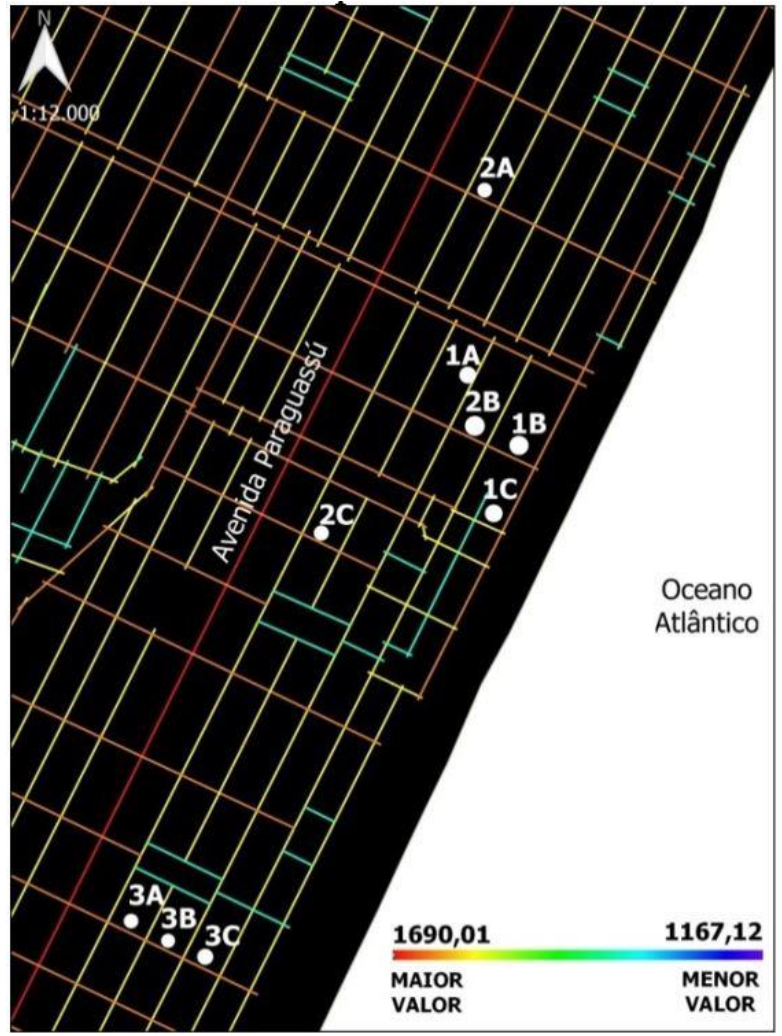

Figura 10 - Integração global (Rn) nas nove quadras. Fonte: Autores (2017).

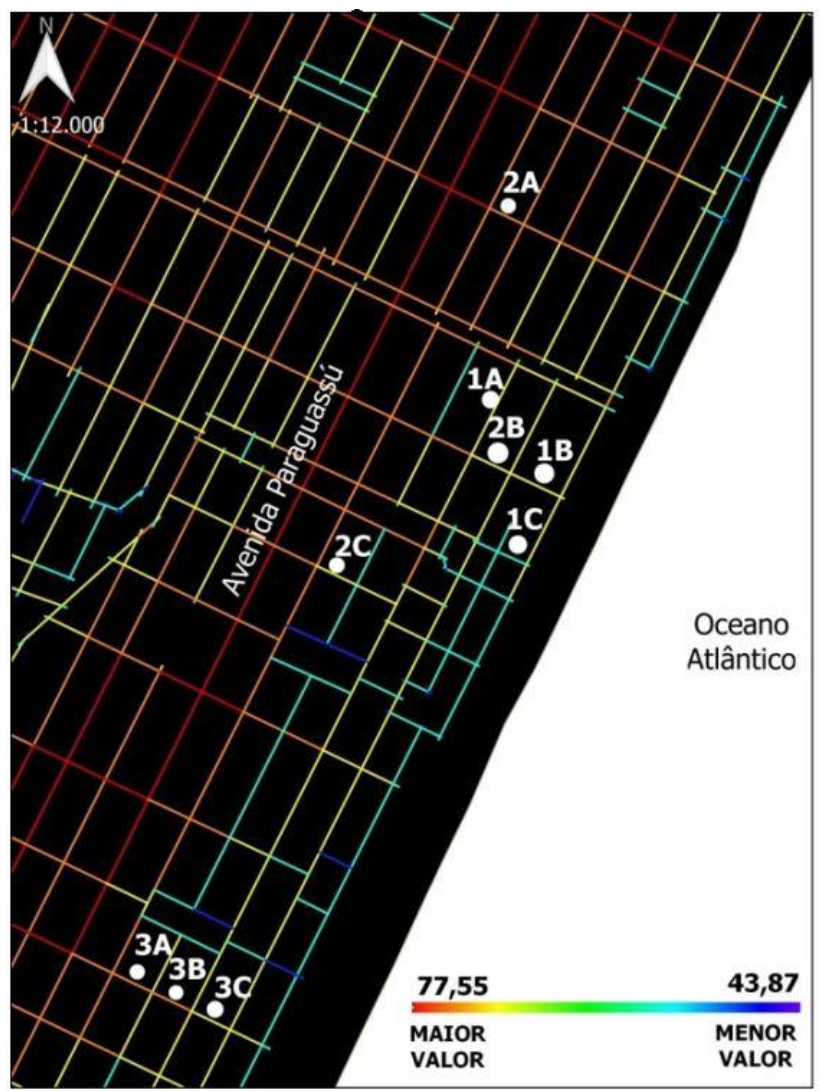

Figura 11 - Integração local (R5) nas nove quadras. Fonte: Autores (2017). 
Tabela 11 - Medidas sintáticas da análise angular

\begin{tabular}{clcc}
\hline Tipos de quadras & & Integração global (Rn) & Integração local (R5) \\
\hline Tipo 1 & $\mathrm{A}$ & 1333,19 & 53,84 \\
Predominância de edifícios residenciais com portas e & $\mathrm{B}$ & 1657,40 & 58,49 \\
janelas voltadas para a rua & $\mathrm{C}$ & 1167,12 & 43,87 \\
\hline Tipo 2 & $\mathrm{A}$ & 1690,01 & 77,55 \\
Predominância de edifícios residenciais com & $\mathrm{B}$ & 1657,28 & 61,57 \\
comércios e serviços nos térreos & $\mathrm{C}$ & 1520,65 & 60,88 \\
\hline Tipo 3 & $\mathrm{A}$ & 1549,89 & 74,38 \\
Predominância de edifícios com portas de garagem & $\mathrm{B}$ & 1549,89 & 67,87 \\
e paredes sem aberturas nos térreos & $\mathrm{C}$ & 1549,83 & 59,56 \\
\hline
\end{tabular}

Fonte: Autores (2017).

As taxas de movimento de veículos tendem a revelar falta de relação com as taxas de movimento de pedestres (Tabela 6), indicando que o movimento de veículos depende muito mais das características configuracionais do espaço urbano (p. ex., nível de acessibilidade/integração de uma via) do que de características locais de uma quadra, como permeabilidade visual e tipos de usos. Tais considerações são sustentadas pela inexistência de correlações (Pearson) entre as taxas de movimento de pedestres e de veículos em cada tipo de quadra e em cada turno, assim como quando as nove quadras foram consideradas (sem distinção por tipo de quadra) no teste de correlação. Nesse sentido, a quadra tipo 2B (com predominância de comércios e serviços nos térreos) possui uma das maiores taxas de movimento de veículos por se tratar de uma grande avenida que serve de acesso ao centro da cidade e à beira da praia.

Não foram encontradas correlações (Pearson) entre as taxas de movimento de veículos e as medidas de integrações global e local por tipo de quadra e turno. Contudo, foi verificada correlação entre taxas de movimento de veículos no turno da manhã e valores de integração global (Rn) (coeficiente de Pearson $=0,694$; sig. $=0,038$ ), quando consideradas as nove quadras no teste de correlação, sem distinção por tipo de quadra.

\section{Avaliação de preferência das interfaces térreas no tocante à percepção de segurança quanto à ocorrência de crimes}

Não foram encontradas diferenças estatisticamente significativas (Teste de Kendall's W) quanto à percepção da rua mais segura entre aquelas apresentadas nas cenas do bloco 1 (Figura 5), tanto no teste realizado com o total de respondentes (40) quanto nos testes realizados apenas com os respondentes de cada uma das três quadras. No entanto, a rua retratada pela cena B (térreos com comércios e serviços) é percebida como a mais segura pelo total da amostra, tendo sido ordenada como tal por 15 dos 40 respondentes (37,5\%; Tabela 12), em razão, fundamentalmente, da "existência de comércios e serviços" (60\% - 9 de 15) e da existência de movimento de pessoas (26,7\% - 4 de 15; Tabela 13). Por outro lado, a rua da cena $\mathrm{C}$ (térreos com paredes cegas e portas de garagem) é percebida como a menos segura, tendo sido indicada como tal por 20 dos 40 respondentes (50\%), em razão, principalmente, da existência de portas de garagem e/ou paredes cegas nas interfaces térreas dos edifícios (40\% - 8 de 20) e da impossibilidade de ser socorrido (20\% - 4 de 20; Tabela 14). Esses resultados tendem a se repetir para os respondentes das quadras tipos 1 e 2 (Tabela 12). Entretanto, predomina entre os respondentes ( 6 de $13-46,2 \%$ ) das quadras tipo 3 a indicação da cena C (térreos com paredes cegas e portas de garagem) como a mais segura. No entanto, essa cena também é a mais mencionada como menos segura (5 de $13-38,5 \%$ ) por respondentes desse tipo de quadra, com a cena A, que representa térreos com portas e janelas voltadas para a rua (Tabela 12). 
Tabela 12 - Ordem de preferência em relação à percepção de segurança

\begin{tabular}{|c|c|c|c|c|c|c|}
\hline \multicolumn{7}{|c|}{ Total da amostra (40) } \\
\hline \multirow[b]{2}{*}{$\begin{array}{l}\text { Ordem das } \\
\text { cenas }\end{array}$} & \multicolumn{3}{|c|}{ Bloco 1} & \multicolumn{3}{|c|}{ Bloco 2} \\
\hline & $\begin{array}{c}\text { Cena A } \\
\text { (Portas e janelas } \\
\text { de apartamentos) }\end{array}$ & $\begin{array}{c}\text { Cena B } \\
\text { (Comércio e } \\
\text { serviços) }\end{array}$ & $\begin{array}{c}\text { Cena C } \\
\text { (Garagens e } \\
\text { paredes } \\
\text { cegas) }\end{array}$ & $\begin{array}{c}\text { Cena A } \\
\text { (Garagens e } \\
\text { paredes } \\
\text { cegas) }\end{array}$ & $\begin{array}{c}\text { Cena B } \\
\text { (Portas e janelas } \\
\text { de apartamentos) }\end{array}$ & $\begin{array}{c}\text { Cena C } \\
\text { (Comércio e } \\
\text { serviços) }\end{array}$ \\
\hline lolugar & $13(32,5)$ & $15(37,5)$ & $12(30)$ & $11(27,5)$ & $7(17,5)$ & $22(55)$ \\
\hline 2ㅇ lugar & $12(30)$ & $20(50)$ & $8(20)$ & $9(22,5)$ & $22(55)$ & $9(22,5)$ \\
\hline 3 lugar & $15(37,5)$ & $5(12,5)$ & $20(50)$ & $20(50)$ & $11(27,5)$ & $9(22,5)$ \\
\hline Total & $40(100)$ & $40(100)$ & $40(100)$ & 40(100) & 40(100) & $40(100)$ \\
\hline Mvo K & 2,05 & 1,75 & 2,20 & 2,23 & 2,10 & 1,68 \\
\hline \multicolumn{7}{|c|}{ Respondentes das quadras tipo 1 (10) } \\
\hline lo lugar & $3(30)$ & $4(40)$ & $3(30)$ & $2(20)$ & $3(30)$ & $5(50)$ \\
\hline 20 lugar & $3(30)$ & $6(60)$ & $1(10)$ & $0(0)$ & $7(70)$ & $3(30)$ \\
\hline 3ㅇ lugar & $4(40)$ & $0(0)$ & $6(60)$ & $8(80)$ & $0(0)$ & $2(20)$ \\
\hline Total & $10(100)$ & $10(100)$ & $10(100)$ & 10(100) & 10(100) & $10(100)$ \\
\hline Mvo K & 2,10 & 1,60 & 2,30 & 2,60 & 1,70 & 1,70 \\
\hline Mvo K-W & 21,15 & 18,50 & 21,90 & 25,60 & 14,15 & 21,05 \\
\hline \multicolumn{7}{|c|}{ Respondentes das quadras tipo 2 (17) } \\
\hline lo lugar & $6(35,3)$ & $8(47,1)$ & $3(17,6)$ & $2(11,8)$ & $3(17,6)$ & $12(70,6)$ \\
\hline 20 lugar & $5(29,4)$ & $7(41,2)$ & $5(29,4)$ & $7(41,2)$ & $8(47,1)$ & $2(11,8)$ \\
\hline 30 lugar & $6(35,3)$ & $2(11,8)$ & $9(52,9)$ & $8(47,1)$ & $6(35,3)$ & $3(17,6)$ \\
\hline Total & $17(100)$ & $17(100)$ & $17(100)$ & $17(100)$ & $17(100)$ & $17(100)$ \\
\hline Mvo K & 2,00 & 1,65 & 2,35 & 2,35 & 2,18 & 1,47 \\
\hline Mvo K-W & 19,85 & 18,74 & 22,15 & 21,65 & 21,76 & 17,65 \\
\hline \multicolumn{7}{|c|}{ Respondentes das quadras tipo 3 (13) } \\
\hline lolugar & $4(30,8)$ & $3(23,1)$ & $6(46,2)$ & $7(53,8)$ & $1(7,7)$ & $5(38,5)$ \\
\hline 2olugar & $4(30,8)$ & $7(53,8)$ & $2(15,4)$ & $2(15,4)$ & $7(53,8)$ & $4(30,8)$ \\
\hline 3o lugar & $5(38,5)$ & $3(23,1)$ & $5(38,5)$ & $4(30,8)$ & $5(38,5)$ & $4(30,8)$ \\
\hline Total & $13(100)$ & $13(100)$ & $13(100)$ & $13(100)$ & $13(100)$ & $13(100)$ \\
\hline Mvo K & 2,08 & 2,00 & 1,92 & 1,77 & 2,31 & 1,92 \\
\hline Mvo K-W & 20,85 & 24,35 & 17,27 & 15,08 & 23,73 & 23,81 \\
\hline
\end{tabular}

Os valores entre parênteses referem-se aos percentuais em relação ao total de respondentes que avaliou cada cena em cada grupo; mvo K= média dos valores ordinais obtida pelo teste Kendall's W (os valores menores referem-se às cenas percebidas como mais seguras); mvo K-W = média dos valores ordinais obtida pelo teste Kruskal-Wallis (os valores menores referem-se aos grupos mais satisfeitos); a comparação entre os valores mvo K deve ser feita na horizontal entre as cenas de cada bloco; a comparação entre os valores mvo K-W deve ser feita na vertical entre os três grupos de respondentes para cada cena. Fonte: Autores (2017).

Tabela 13 - Principais justificativas para a escolha da cena com a rua percebida como mais segura

\begin{tabular}{|c|c|c|c|c|}
\hline \multirow{2}{*}{$\begin{array}{l}\text { Indique as principais justificativas para a escolha da cena com a rua percebida } \\
\text { como mais segura do bloco } 1\end{array}$} & \multicolumn{4}{|c|}{ Bloco 1} \\
\hline & $\begin{array}{l}\text { Cena A } \\
13(100)\end{array}$ & $\begin{array}{l}\text { Cena B } \\
15(100)\end{array}$ & $\begin{array}{l}\text { Cena C } \\
12(100)\end{array}$ & $\begin{array}{c}\text { Total } \\
40(100)\end{array}$ \\
\hline Existência de comércios e serviços & $2(16,6)$ & $9(60)$ & $0(0)$ & $11(27,5)$ \\
\hline Existência de portas e janelas voltadas para a rua & $8(61,5)$ & $1(6,7)$ & $0(0)$ & $9(22,5)$ \\
\hline Existência de movimento de pessoas & $2(15,4)$ & $4(26,7)$ & $2(15,4)$ & $8(20)$ \\
\hline Tamanho adequado do passeio público & $0(0)$ & $3(20)$ & $4(33,3)$ & $7(17,5)$ \\
\hline Inexistência de portas de garagem e/ou paredes cegas & $2(15,4)$ & $1(6,7)$ & $0(0)$ & $3(7,5)$ \\
\hline Existência de portas de garagem e/ou paredes cegas & $0(0)$ & $0(0)$ & $2(16,7)$ & $2(5)$ \\
\hline Existência de dispositivos de segurança (câmeras de segurança/ & 1 & 0 & 1 & 2 \\
\hline cercamento/porteiro) & $(7,7)$ & (0) & $(8,3)$ & (5) \\
\hline Inexistência de movimento de pessoas & $1(7,7)$ & $0(0)$ & $1(8,3)$ & $2(5)$ \\
\hline \multirow{2}{*}{$\begin{array}{l}\text { Indique as principais razões que justifiquem a escolha da cena com a rua percebida } \\
\text { como mais segura do bloco } 2\end{array}$} & \multicolumn{4}{|c|}{ Bloco 2} \\
\hline & $\begin{array}{l}\text { Cena A } \\
11(100)\end{array}$ & $\begin{array}{l}\text { Cena B } \\
7(100)\end{array}$ & $\begin{array}{l}\text { Cena C } \\
22(100)\end{array}$ & $\begin{array}{c}\text { Total } \\
40(100)\end{array}$ \\
\hline Existência de comércios e serviços & $1(9,1)$ & $0(0)$ & $19(86,4)$ & $20(50)$ \\
\hline Existência de movimento de pessoas & $1(9,1)$ & $0(0)$ & $8(36,4)$ & $9(22,5)$ \\
\hline Existência de portas e janelas voltadas para a rua & $0(0)$ & $2(28,6)$ & $2(9,1)$ & $4(10)$ \\
\hline Existência de portas de garagem e/ou paredes cegas & $3(27,3)$ & $0(0)$ & $0(0)$ & $3(7,5)$ \\
\hline Inexistência de comércios e serviços & $0(0)$ & $2(28,6)$ & $0(0)$ & $2(5)$ \\
\hline
\end{tabular}


Tabela 13 - Continuação...

\begin{tabular}{ccccc}
\hline \multirow{2}{*}{$\begin{array}{c}\text { Indique as principais razões que justifiquem a escolha da cena com a rua percebida } \\
\text { como mais segura do bloco } 2\end{array}$} & \multicolumn{3}{c}{ Bloco 2 } \\
\cline { 2 - 5 } & Cena A & Cena B & Cena C & Total \\
& $11(100)$ & $\mathbf{7 ( 1 0 0 )}$ & $\mathbf{2 2 ( 1 0 0 )}$ & $\mathbf{4 0 ( 1 0 0 )}$ \\
\hline Tamanho adequado do passeio público & $2(18,2)$ & $0(0)$ & $0(0)$ & $2(5)$ \\
Inexistência de portas de garagem e/ou paredes cegas & $0(0)$ & $2(28,6)$ & $0(0)$ & $2(5)$ \\
Ambiente familiar & $0(0)$ & $1(14,3)$ & $1(4,5)$ & $2(5)$ \\
Menos conexão entre os edifícios e o espaço público & $2(18,2)$ & $0(0)$ & $0(0)$ & $2(5)$ \\
\hline
\end{tabular}

Os valores entre parênteses referem-se aos percentuais em relação ao total de respondentes que escolheu cada cena de rua percebida como mais segura e ao total da amostra de respondentes in loco. Fonte: Autores (2017).

Tabela 14 - Principais justificativas para a escolha da cena com a rua percebida como menos segura

\begin{tabular}{|c|c|c|c|c|}
\hline \multirow[b]{2}{*}{$\begin{array}{l}\text { Indique as principais razōes que justifiquem a escolha da cena com a rua } \\
\text { percebida como menos segura do bloco } 1\end{array}$} & \multicolumn{4}{|c|}{ Bloco 1} \\
\hline & $\begin{array}{l}\text { Cena A } \\
15(100)\end{array}$ & $\begin{array}{l}\text { Cena B } \\
5(100)\end{array}$ & $\begin{array}{l}\text { Cena C } \\
20(100)\end{array}$ & $\begin{array}{c}\text { Total } \\
40(100)\end{array}$ \\
\hline $\begin{array}{c}\text { Existência de portas de garagem e/ou paredes cegas } \\
\text { Inexistência de movimento de pessoas } \\
\text { Existência de comércios e serviços } \\
\text { Inexistência de comércios e serviços } \\
\text { Impossibilidade de ser socorrido } \\
\text { Existência de portas e janelas voltadas para a rua } \\
\text { Existência de lugar para se esconder } \\
\text { Tamanho inadequado do passeio público } \\
\text { Inexistência de portas e janelas voltadas para a rua } \\
\text { Inexistência de portas de garagem e/ou paredes cegas } \\
\text { Existência de vegetação }\end{array}$ & $\begin{array}{c}0(0) \\
3(20) \\
0(0) \\
1(6,7) \\
0(0) \\
1(6,7) \\
1(6,7) \\
3(20) \\
0(0) \\
1(6,7) \\
2(13,3) \\
\end{array}$ & $\begin{array}{l}1(20) \\
0(0) \\
4(80) \\
0(0) \\
0(0) \\
1(20) \\
1(20) \\
0(0) \\
0(0) \\
1(20) \\
0(0)\end{array}$ & $\begin{array}{l}8(40) \\
3(15) \\
1(5) \\
3(15) \\
4(20) \\
1(5) \\
1(5) \\
0(0) \\
2(10) \\
0(0) \\
0(0) \\
\end{array}$ & $\begin{array}{c}9(22,5) \\
6(15) \\
5(12,5) \\
4(10) \\
4(10) \\
3(7,5) \\
3(7,5) \\
3(7,5) \\
2(5) \\
2(5) \\
2(5) \\
\end{array}$ \\
\hline \multirow{2}{*}{$\begin{array}{l}\text { Indique as principais razões que justifiquem a escolha da cena com a rua } \\
\text { percebida como menos segura do bloco } 2\end{array}$} & \multicolumn{4}{|c|}{ Bloco 2} \\
\hline & $\begin{array}{l}\text { Cena A } \\
20(100) \\
\end{array}$ & $\begin{array}{l}\text { Cena B } \\
11(100) \\
\end{array}$ & $\begin{array}{l}\text { Cena C } \\
9(100) \\
\end{array}$ & $\begin{array}{c}\text { Total } \\
40(100) \\
\end{array}$ \\
\hline $\begin{array}{c}\text { Existência de portas de garagem e/ou paredes cegas } \\
\text { Inexistência de movimento de pessoas } \\
\text { Existência de comércios e serviços } \\
\text { Inexistência de comércios e serviços } \\
\text { Impossibilidade de ser socorrido } \\
\text { Existência de portas e janelas voltadas para a rua } \\
\text { Ausência de apropriação do espaço pelo morador } \\
\text { Inexistência de portas e janelas voltadas para a rua } \\
\text { Existência de locais para se esconder } \\
\text { Próximo da praia } \\
\text { Acessos de veículos às garagens atuam como obstáculos }\end{array}$ & $\begin{array}{l}12(60) \\
4(20) \\
0(0) \\
2(10) \\
3(15) \\
0(0) \\
0(0) \\
2(10) \\
0(0) \\
0(0) \\
2(10)\end{array}$ & $\begin{array}{l}0(0) \\
4(36,4) \\
0(0) \\
3(27,3) \\
2(18,2) \\
0(0) \\
2(18,2) \\
0(0) \\
2(18,2) \\
2(18,2) \\
0(0)\end{array}$ & $\begin{array}{l}1(11,1) \\
0(0) \\
5(55,6) \\
0(0) \\
0(0) \\
3(33,3) \\
1(11,1) \\
1(11,1) \\
1(11,1) \\
0(0) \\
0(0)\end{array}$ & $\begin{array}{l}13(32,5) \\
8(20) \\
5(12.5) \\
5(12,5) \\
5(12,5) \\
3(7,5) \\
3(7,5) \\
3(7,5) \\
3(7,5) \\
2(5) \\
2(5)\end{array}$ \\
\hline
\end{tabular}

Os valores entre parênteses referem-se aos percentuais em relação ao total de respondentes que escolheu cada cena de rua percebida como menos segura e ao total da amostra de respondentes in loco. Fonte: Autores (2017).

No tocante à indicação da cena com a rua percebida como mais segura no bloco 2, foram encontradas diferenças estatisticamente significativas em relação às indicações pela amostra total de respondentes (Kendall's W, $\mathrm{Chi}^{2}=6,650$, sig $=0,036$ ) e pelo grupo de usuários das quadras tipo 2 (Kendall's W, $\mathrm{Chi}^{2}=7,412$, sig $=0,025$ ) (Tabela 12). Para a maioria desses respondentes (respectivamente, 55\% - 22 de 40 - e 70,6\% - 12 de 17), a rua representada pela cena C (térreos com comércios e serviços) foi percebida como a mais segura, também tendo como principal justificativa a "existência de comércios e serviços" (86,4\% - 19 de 22), seguida da "existência de movimento de pessoas" (36,4\% - 8 de 22$)$ (Tabela 13). Por outro lado, a cena com a rua representando térreos com paredes sem abertura e portas de garagem (cena A) predomina como aquela percebida como a menos segura pelo total da amostra e, especificamente, pelos respondentes das quadras tipo 2 (respectivamente, $50 \%$ - 20 de 40 - e 47,1\% - 8 de 17) pela razão principal da "existência de portas de garagem e/ou paredes cegas" (60\% - 12 de 20), seguida da "inexistência de movimento de pessoas" (20\% - 4 de 20) (Tabela 14).

Além disso, apesar de não haver diferença estatisticamente significativa (Teste de Kendall's W), esses resultados tendem a se repetir também entre o grupo de usuários das quadras do tipo 1. Por outro lado, 
mesmo não havendo uma diferença estatisticamente significativa (Teste de Kendall's W) entre as indicações dos respondentes das quadras do tipo 3, a rua da cena A (térreos com paredes cegas e portas de garagem) predomina como aquela percebida como mais segura (7 de $13-53,8 \%$ ), enquanto a rua da cena B (térreos com portas e janelas voltadas para a rua) predomina como a menos segura (5 de 13 - 38,5\%). Contudo, não foram encontradas diferenças estatisticamente significativas (Teste de Kruskal-Wallis; Tabela 12) entre as indicações das cenas com as ruas percebidas como mais e menos seguras pelos respondentes de cada um dos três tipos de quadra utilizada.

\section{Avaliação da ocorrência de crimes nas quadras}

Por meio de relatos de moradores, veranistas e pessoas que trabalham nas quadras avaliadas, $30 \%$ (12 de 40) de todos os respondentes mencionam ter conhecimento da ocorrência de pelo menos um dos seguintes tipos de crime: roubo em residência, furto em residência, roubo de veículo, furto de veículo, furto em veículo ou roubo a pedestre (Tabela 15). 0 roubo em residência é o mais mencionado (38,9\% - 14 de 36 das ocorrências) e tende a ocorrer durante a noite (50\% - 7 de 14), seguido pelo roubo a pedestre $(22,2 \%$ - 8 de 36 das ocorrências), que também tende a acontecer durante a noite $(62,5 \%$ - 5 de 8$)$, e pelo de furto em residência (16,7\% - 6 de 36), que tende a ocorrer de madrugada (50\% - 3 de 6$)$ ou à noite $(33 \%$ - 2 de 6$)$.

Tabela 15 - Total de registros dos turnos e dos tipos de crimes ocorridos

\begin{tabular}{cccccc}
\hline Tipo de crime & Manhã & Tarde & Noite & Madrugada & Total \\
\hline \multicolumn{7}{c}{ Total da amostra } \\
\hline Roubo em residência & $2(28,6)$ & $3(60)$ & $7(43,7)$ & $2(25)$ & $14(38,9)$ \\
Furto em residência & $0(0)$ & $1(20)$ & $2(12,5)$ & $3(37,5)$ & $6(16,7)$ \\
Roubo de veículo & $2(28,6)$ & $0(0)$ & $2(12,5)$ & $0(0)$ & $4(11,1)$ \\
Furto de veículo & $1(14,3)$ & $0(0)$ & $0(0)$ & $3(37,5)$ & $4(11,1)$ \\
Furto em veículo & $0(0)$ & $0(0)$ & $0(0)$ & $0(0)$ & $0(0)$ \\
Roubo a pedestre & $2(28,6)$ & $1(20)$ & $5(31,2)$ & $0(0)$ & $8(22,2)$ \\
Total & $7(100)$ & $5(100)$ & $16(100)$ & $8(100)$ & $36(100)$ \\
\hline
\end{tabular}

Os valores entre parênteses referem-se aos percentuais em relação ao total de crimes ocorridos conforme o tipo e o turno de ocorrência. Fonte: Autores (2017).

As taxas mais altas de roubo em residências tendem a ocorrer no turno da noite, nas quadras $3 \mathrm{~A}$ $(0,67), 3 \mathrm{C}(0,50)$ e na quadra $2 \mathrm{~A}(0,60)$, onde tal tipo de crime também tende a ocorrer no turno da tarde $(0,60)$ e da manhã $(0,40)$. A quadra 2B é a única que apresenta roubo em residência durante a madrugada $(0,33)$. Os furtos em residências acontecem durante a noite na quadra $3 C(0,5)$ e durante a madrugada $(0,5)$ e à tarde $(0,17)$ na quadra $2 \mathrm{~B}$. A taxa mais alta de roubo a pedestre acontece na quadra $3 \mathrm{C}$ à noite $(0,065)$, seguida dessa taxa à noite $(0,052)$ na quadra $1 \mathrm{~A}$. Os demais roubos a pedestres ocorrem na quadra $1 \mathrm{~B}$ durante a tarde $(0,045)$ e pela manhã $(0,037)$, e na quadra $2 \mathrm{~B}$, pela manhã $(0,031)$ e à noite $(0,02)$. Logo, mesmo que não tenha sido mencionada a ocorrência de crimes durante os períodos da manhã, tarde e madrugada nas quadras tipo 3 (predomínio de edificações residenciais com portas de garagem e paredes cegas nos térreos), estas são aquelas que tendem a ter a maior taxa de roubo (44,4\% das ocorrências nas quadras tipo 3$)$ e de furto em residências $(22,2 \%$ das ocorrências criminais nesse tipo de quadra) e de roubo a pedestres $(33,3 \%$ das ocorrências nesse tipo de quadra) no turno da noite. Portanto, a existência de câmeras de segurança na maioria dos edifícios dessas quadras, o fato de a delegacia de polícia da cidade estar localizada a distâncias que variam entre três e cinco quadras das três quadras tipo 3 (em comparação a distâncias entre 13 e 14 quadras das quadras tipo 1 e a distâncias entre 9 e 13 quadras das quadras tipo 2) e um entrevistado da quadra 3C ter mencionado: "Me sinto seguro porque a delegacia de Capão da Canoa fica aqui perto e todos os prédios têm câmeras voltadas para a rua" não parecem ter sido suficientes para superar o efeito negativo sobre a segurança durante a noite gerado pela predominância de portas de garagens e paredes cegas. 
Por outro lado, os respondentes das quadras do tipo 2 são os que mais mencionam o fato de a quadra ser segura como uma de suas principais características (7 de 15 - 46,7\%), enquanto tal característica foi mencionada por apenas um (1 de $9-11,11 \%)$ respondente das quadras tipo 1 e dois (de $10-20 \%$ ) respondentes das quadras tipo 3, o que parece estar relacionado ao maior controle visual do espaço aberto público e a mais movimento de pedestres nos horários nos quais o comércio e serviços estão abertos nas quadras tipo 2. Embora um entrevistado da quadra 1B tenha mencionado: "Não me sinto seguro nessa rua. As entradas de vários edifícios são recuadas, possibilitando que os criminosos se escondam".

Os respondentes das quadras tipo 1 (predomínio de edificações com térreos com portas e janelas voltadas para a rua) são os que menos mencionam ocorrências criminais (4 de 36 - 11,1\%), o que pode estar relacionado às maiores conexões funcional e visual entre as interfaces térreas dos edifícios e o espaço urbano.

\section{Conclusões}

Os resultados apresentados revelam o impacto negativo das alterações nos usos nos pavimentos térreos (de usos residencial e comercial para uso destinado à garagem) e a consequente redução das permeabilidades física e visual entre as interfaces térreas das edificações e os espaços abertos públicos. Tal impacto negativo reflete-se na redução do uso de tais espaços pelos pedestres. Apesar de os três tipos de quadras serem bastante utilizadas durante o dia, as quadras com predomínio de edificações residenciais, com portas e janelas voltadas para a rua e as quadras com predomínio de edificações residenciais com comércios e serviços nos térreos, são as mais utilizadas pelos moradores e veranistas. Embora no período da noite o uso dos três tipos de quadra diminua, as quadras com predomínio de comércios e serviços nos térreos são as mais utilizadas por moradores e veranistas.

Ainda, as quadras com predomínio de comércios e serviços nos térreos apresentam as maiores taxas de movimento de pedestre durante a manhã, tarde e noite. Esses resultados sustentam a afirmação de que a existência de relação direta entre as edificações e os espaços abertos, por meio de conexões físicas e visuais e com usos nos pavimentos térreos que contribuem para a dinâmica urbana (p. ex., restaurantes, sorveterias), tende a contribuir para a presença de pessoas e consequente vitalidade urbana (Reis, 2014). Essas quadras também são caracterizadas por percentuais maiores de recuos frontais utilizados como áreas de estar, incrementando o uso do espaço aberto público, conforme já destacado em outros estudos (Santos \& Vogel, 1985). Ainda, o movimento de pedestres também é determinado pelas características de acessibilidade das quadras em servirem ou não como rotas de acesso à praia e ao centro da cidade.

Por sua vez, as taxas de movimento de pedestres tendem a ser menores nas quadras com predomínio de edificações residenciais com portas de garagem e paredes sem aberturas nos térreos, reforçando resultados de outros estudos que evidenciam que a inexistência de conexões funcionais e visuais tende a afetar negativamente o tipo e a intensidade de uso do espaço urbano, que passa a ser utilizado quase que exclusivamente como passagem (p. ex., Becker \& Reis, 2004). Assim, esses resultados corroboram o fato, já destacado por Gehl (2009), de que a presença de pessoas em um ambiente tende a ser fundamental para atrair outros usuários, com espaços desertos tendendo a ser evitados.

Os resultados também indicam que os segmentos mais integrados globalmente, por se encontrarem em avenidas mais largas e menos sombreadas, tendem a ter menos movimento de pedestres à tarde, durante o final de outubro e no início de novembro em Capão da Canoa do que segmentos menos integrados em vias mais estreitas e sombreadas. Ainda, os segmentos mais integrados globalmente tendem a ter mais movimento de veículos durante o turno da manhã. Logo, tais resultados revelam o impacto do clima na circulação de pedestres e também estão em consonância com o fato de que ruas largas estimulam o trânsito de veículos em alta velocidade, enquanto ruas estreitas contribuem para um bairro mais caminhável (Gaete, 2016). Esses resultados também revelam que o movimento de pedestres em certo período do dia pode ser mais determinado pelo tipo de uso e pelos níveis de permeabilidades física e visual dos pavimentos térreos das edificações do que pelas características configuracionais dos 
segmentos, não corroborando, pelo menos em parte, a afirmação de que as ruas mais integradas são as mais utilizadas pelos pedestres (Hillier \& Hanson, 1984).

No tocante à segurança quanto à ocorrência de crimes, as cenas com as ruas percebidas como mais seguras pela maioria dos respondentes são as que representam as quadras com predomínio de comércios e serviços nos térreos, em razão, justamente, da existência de comércios e serviços e do movimento de pessoas. Adicionalmente, em relação à avaliação da ocorrência de crimes nas quadras, os usuários das quadras com predomínio de comércios e serviços nos térreos são os que mais mencionam a segurança como uma das principais características dessas quadras. Tais resultados sustentam que a existência de comércios e serviços confere a esses espaços mais percepção de segurança, pois está relacionada a mais vigilância natural do espaço aberto público promovida pelo movimento de pedestres, conforme já destacado em outros estudos (Hillier \& Sahbaz, 2005).

Por outro lado, as cenas com as ruas que representam as quadras com predomínio de edificações residenciais com portas de garagem e paredes sem aberturas nos térreos são percebidas pela maioria dos respondentes como as menos seguras, em razão, principalmente, da existência de tais portas de garagem e/ou paredes cegas e da impossibilidade de ser socorrido. Soma-se o fato de que, segundo o conhecimento dos usuários quanto à ocorrência de crimes, esse tipo de quadra tende a ter a maior taxa de roubo e de furto em residências e de roubo a pedestres no turno da noite, o turno com mais ocorrências de crimes em qualquer um dos três tipos de quadras, corroborando a afirmação de que a baixa supervisão das residências a partir da rua ou de edificações vizinhas cria oportunidades para o criminoso agir sem ser notado (Jacobs, 2009).

Assim sendo, os resultados desta investigação possibilitam mais compreensão dos impactos das transformações nas interfaces térreas das edificações, resultantes da expansão urbana de cidade litorânea, no uso dos espaços abertos públicos, na segurança quanto à ocorrência de crimes em tais espaços públicos e em unidades residenciais adjacentes. Espera-se que tais resultados possam contribuir para o planejamento urbano e a elaboração de leis e normas que regulamentem as características das interfaces térreas das edificações visando à criação de espaços urbanos mais seguros e convidativos ao uso pelos pedestres.

\section{Referências}

Antocheviz, F. B., Arsego, C., Braga, A. da C., Reis, A. T. L., \& Zampieri, F. (2017). Urban transformations in a coastal city and movement of people in public open spaces. In A. Gospodini (Ed.), Proceedings of the International Conference on Changing Cities III Spatial, Design, Landscape \& Socio-economic Dimensions Under (Vol. 3, pp. 965976). Syros-Delos-Mykonos Islands, Greece: University of Thessaly.

Atlas Brasil. (2013). Capão da Canoa - RS. Recuperado em 5 de maio de 2017, de http://atlasbrasil.org.br/2013/pt/perfil_m /capao-da-canoa_rs

Becker, D., \& Reis, A. T. L. (2004). O impacto das barreiras físicas de condomínios horizontais fechados no espaço urbano. In Anais da I Conferência Latino Americana de Construção Sustentável, X Encontro Nacional de Tecnologia do Ambiente Construído. São Paulo: ANTAC.

Bentley, I., Alcock, A., Murrian, P., McGlynn, S., \& Smith, G. (1985). Responsive environments: a manual for designer. London: Architectural Press.

Caldeira, T. P. R. (2003). Cidade de muros: crimes, segregação e cidadania em São Paulo (2. ed.). São Paulo: Editora 34.

Espínola, A. M. (2013). Transformações na Zona Costeira: um estudo das relações entre economia, turismo e urbanização (Tese de doutorado). Faculdade de Arquitetura, Universidade Federal do Rio Grande do Sul, Porto Alegre.

Gaete, C. M. (2016). 5 fatores que tornam os bairros caminháveis. ArchDaily. Recuperado em 31 de janeiro de 2017, de http://www.archdaily.com.br/br/801403/5-fatores-que-tornam-os-bairros-caminhaveis 
Gehl, J. (2009). La humanizacion del espacio urbano. Barcelona: Editorial Reverté S.A.

Gehl, J. (2010). Cities for people. Washington: Island Press.

Hillier, B., \& Hanson, J. (1984). The social logic of space. Cambridge: Cambridge University Press. http://dx.doi.org/10.1017/CB09780511597237.

Hillier, B., \& Sahbaz, O. (2005). High resolution analysis of crime patterns in urban street networks: an initial statistical sketch from an ongoing study of a London borough. In Proceedings of the 5th Space Syntax Symposium Delf (pp. 451-478). Delft: University of Delft.

Hillier, B., \& Vaughan, L. (2007). The city as one thing. Progress in Planning, 67(3), 205-230.

Hillier, B., Yang, T., \& Turner, A. (2012). Normalising least angle choice in Depthmap and it opens up new perspectives on the global and local analysis of city space. Journal of Space Syntax, 3(2), 155-193.

Holston, J. (1993). A cidade modernista: uma crítica de Brasília e sua utopia. São Paulo: Companhia das Letras. Jacobs, J. (2009). Morte e vida de grandes cidades (2. ed.). São Paulo: WMF Martins Fontes.

Lay, M. C. D., \& Reis, A. T. (2005). Análise quantitativa na área de estudos ambiente-comportamento. Revista Ambiente Construído, 5(2), 21-36.

Moraes, A. C. R. (1999). Contribuição para a gestão da zona costeira do Brasil: elementos para uma geografia do litoral brasileiro. São Paulo: Hucitec.

Reis, A. T. (2014). Forma urbana tradicional e modernista: uma reflexão sobre o uso e estética dos espaços urbanos. Arquisur Revista, (6), 70-87.

Reis, A. T., \& Dittmar, C. (2009). An analysis of crime occurrence, security perception and aspects of residential areas. In Anais do $40^{\circ}$ EDRA (pp. 31-38). Kansas City: University of Kansas.

Reis, A. T., \& Lay, M. C. (2006). Avaliação da qualidade de projetos: uma avaliação perceptiva e cognitiva. Ambiente Construído, 6(3), 21-34.

Rohmer, M. (2015). Incorporando prédios. In H. Karssenber, J. Laven, M. Glaser, \& M. Hoff (Eds.), A cidade ao nível dos olhos: lições para os plinths (2. ed., pp. 106-110). Porto Alegre: EdiPUCRS.

Santos, C., \& Vogel, A. (1985). Quando a rua vira casa: a apropriação de espaços de uso coletivo em um centro de bairro. São Paulo: Projeto.

Siegel, S. (1975). Estatística não paramétrica para as ciências do comportamento. São Paulo: McGraw-Hill do Brasil.

Vieira, L. B. (2002). Influência do espaço construído na ocorrência de crimes em conjuntos habitacionais (Dissertação de mestrado). Universidade Federal do Rio Grande do Sul, Porto Alegre.

Editor: Rodrigo Firmino

Recebido: Dez. 11, 2017

Aprovado: Jul. 23, 2018 